CUADERNOS DE ESTUDIOS GALLEGOS, LVIII N. ${ }^{\circ} 124$, enero-diciembre (2011), pp. 197-234

ISSN 0210-847 X

\title{
"JUNTOS EN UNA CASA DEBAJO DEL PODERÍO PATERNAL": LA FAMILIA EN LA JURISDICCIÓN DE SAN CLODIO DO RIBEIRO DE AVIA A FINALES DEL SIGLO XVI
}

Frutos FERnÁNDEZ GonZÁleZ

IES $n^{\circ} 1$ de $O$ Carballiño

Francisco Sandoval Verea

Arquivo Histórico Provincial de Ourense 


\title{
"JUNTOS EN UNA CASA DEBAJO DEL PODERÍO PATERNAL": LA FAMILIA EN LA JURISDICCIÓN DE SAN CLODIO DO RIBEIRO DE AVIA A FINALES DEL SIGLO XVI
}

\begin{abstract}
RESUMEN
La fisonomía de la familia gallega en el siglo XVIII es bien conocida gracias, en gran medida, al Catastro de Ensenada. Sin embargo, la escasez de fuentes comparables para los siglos precedentes mantiene en la penumbra la caracterización de los hogares gallegos de buena parte de la Edad Moderna. Esta circunstancia, permite calibrar el valor de un documento como el padrón de San Clodio de 1580, que ofrece una detallada instantánea del universo familiar en la jurisdicción ourensana del mismo nombre, sita en el Ribeiro de Avia, una comarca vitícola muy pujante durante el siglo XVI. Con el complemento de otras fuentes coetáneas, en este artículo se esboza un fresco de la realidad económica y demográfica de este territorio que nos ayuda a enmarcar una tipología familiar con trazos bien definidos y con notables diferencias estructurales al respecto de la conocida para mediados del siglo XVIII.
\end{abstract}

PALABRAS ClAVE: Galicia, Ourense, Ribeiro de Avia, familia, economía vitícola, siglo XVI.

\section{"JUNTOS EN UNA CASA DEBAJO DEL PODERÍO PATERNAL": FAMILIES FROM SAN CLODIO DO RIBEIRO DE AVIA AT THE END OF $16^{\mathrm{TH}}$ CENTURY.}

\begin{abstract}
The features of the Galician family in the $18^{\text {th }}$ century are well known, to a large extent, thanks to the Ensenada Cadastre. However, the few comparable sources about the previous period hampers an accurate description of Galician homes throughout most of the Modern Age. This circumstance makes it possible to measure the value of a document as San Clodio census from 1580, shows a detailed picture of the domestic universe of the homonymous district in Ourense, located in Ribeiro de Avia, a very booming vine growing area during the $16^{\text {th }}$ century. With the aid of some other contemporary sources, this article outlines a portrayal of the economic and demographic reality of this region, which helps us to frame a family pattern with welldefined features and remarkable differences as compared with that of the mid $18^{\text {th }}$ century.
\end{abstract}

KEY WORDS: Galicia, Ourense, Ribeiro de Avia, family, household, vine growing economy, $16^{\text {th }}$ century . 
Recibido/Received: 06/05/2010

Aceptado/Accepted: 27/07/2011

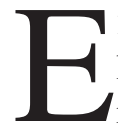

L papel cardinal que ha desempeñado la familia en la socialización de los individuos y en la articulación de las sociedades tradicionales ha atraído, desde hace varias décadas, la atención de las Ciencias Sociales y las Humanidades que, a través de un incontable número de trabajos, han puesto de relieve la centralidad del grupo doméstico en los procesos de reproducción social. Si bien en España el grado de desarrollo de estos estudios es territorialmente dispar, la producción historiográfica en torno al tema es muy nutrida, en particular la referida a la época moderna, y en los últimos años ha ampliado sus horizontes a otros aspectos de las relaciones sociales y económicas propias del universo familiar que rebasan el estricto ámbito corresidencial ${ }^{1}$. En Galicia los primeros trabajos vieron la luz a finales de la década de los ochenta ${ }^{2}$; desde en-

\footnotetext{
${ }^{1}$ En el espacio de estas líneas resulta vana cualquier pretensión de exhaustividad a la hora de referir la abundantísima publicística española sobre la historia de la familia en la Edad Moderna. Citamos sólo algunas de las que recientemente han hecho balance del estado de la cuestión: CHACÓN JIMÉNEZ, Francisco y HERNÁNDEZ FRANCO, Juan, (eds.), Espacios sociales, universos familiares. La familia en la historiografía española. Murcia, 2007; GARCÍA GONZÁLEZ, Francisco (coord.) La historia de la familia en la Península Ibérica. Balance regional y perspectivas «Homenaje A Peter Laslett», Cuenca, 2008.

2 DUBERT GARCÍA, Isidro (Los comportamientos de la familia urbana en la Galicia del Antiguo Régimen,. El ejemplo de Santiago de Compostela, Santiago, 1987; Historia de la familia en Galicia durante la época moderna, 1550-1830: estructura, modelos hereditarios y conflictividad. A Coruña-Sada, 1992), FERNÁNDEZ CORTIZO, Camilo (“A una misma mesa y manteles: la familia en Tierra de Montes en el siglo XVIII" en Cuadernos de Estudios Gallegos, XXXIII (1982), 237 276; "En casa y compañía: grupo doméstico y estrategias familiares en la Galicia occidental a mediados del siglo XVIII", en BERMEJO BARRERA, J.C. (coord.), Parentesco, familia y matrimonio en la Historia de Galicia, Santiago de Compostela, 1989, 145-165; "Estrategias familiares y pequeña explotación campesina en la Galicia del siglo XVIII", en SAAVEDRA, Pegerto y VILLARES, Ramón (eds.), Señores y campesinos en la Península Ibérica, siglos XVIII-XX. 2. Campesinado y pequeña explotación, Barcelona, 1991, 310-345); y SAAVEDRA, Pegerto ("Casa y comunidad en la Galicia interior, 1750-1860"; en BERMEJO BARRERA, J.C. (coord.), Parentesco, cit., 95-143; este artículo ha sido recopilado, junto a otros por el mismo autor, en Das casas de morada ó monte comunal, Santiago de Compostela, 1996, 19-76. En adelante citaremos por esta última publicación).
} 
tonces distintos estudios de ámbito comarcal han dedicado una parte más o menos amplia al análisis de la familia, para ir completando un puzzle que, a día de hoy, permite tener un aceptable conocimiento de los contrastes del universo familiar gallego del Antiguo Régimen ${ }^{3}$. Pero la generosidad informativa que ofrece el Catastro de Ensenada para el estudio de la fisonomía familiar a mediados del siglo XVIII, y la ausencia de fuentes que presenten la misma fiabilidad y riqueza de datos para otros períodos de la época moderna, han orientado hacia ese momento histórico la mayor parte de las investigaciones. De modo que los siglos XVI y XVII presentan todavía muchas zonas de penumbra. Esta circunstancia permite valorar en su justa medida la singularidad del padrón de San Clodio de 1580 , la fuente principal que utilizamos en este trabajo para el estudio de la familia en el siglo XVI; y eso será así, aunque se refiera a un espacio físico reducido y sólo cuente con referentes coetáneos muy puntuales que impiden aplicar adecuadamente el método comparativo ${ }^{4}$. Por eso, sólo será posible, en general, establecer contrastes con los datos de mediados del XVIII, aun siendo conscientes de que entre una y otra fecha las coyunturas socioeconómicas y demográficas cambiaron substancialmente. En todo caso, la utilización del mencionado padrón para presentar las características de la población y de la familia

\footnotetext{
${ }^{3}$ Un exhaustivo estado de la cuestión con referencias de todos estos trabajos en PÉREZ GARCÍA, José Manuel, "Familias y hogares en Galicia y en la Cornisa Cantábrica durante el Antiguo Régimen", en GARCÍA GONZÁLEZ, Francisco (coord.) La historia de la familia, cit., 57-84. También una visión panorámica del tema en el noroeste peninsular en SAAVEDRA, Pegerto, "Las lógicas de la organización familiar y reproducción social en la España cantábrica y noratlántica en el Antiguo Régimen", en Historia y perspectivas de investigación. Estudios en memoria del profesor Ángel Rodríguez, Sánchez, Badajoz, 2002, 141-9.; y SOBRADO CORREA, Hortensio, A gran Historia de Galicia. Tomo VI. A Galicia do Antigo Réxime (ca. 1480-ca. 1835). Poboación e economía. Vol. I, A Coruña, 2007. 147-203.

${ }^{4}$ Otros padrones procedentes de las ventas jurisdiccionales del XVI referidos a una sola localidad eran conocidos en Galicia desde hace varias décadas pero, o bien no fueron aprovechados para la historia de la familia (GELABERT, Juan E., Santiago y la Tierra de Santiago de 1500 a 1640: contribución a la Historia Económica y Social de los territorios de la Corona de Castilla en los siglos XVI y XVII, Sada-A Coruña, 1982, 45) o bien no informaban sobre la totalidad de los integrantes del hogar, lo que impedía conocer su tamaño y estructura interna (SAAVEDRA FERNÁNDEZ, Pegerto, Economía política y sociedad en Galicia: la provincia de Mondoñedo, 1480-1830. A Coruña, 1985, 125). Más recientemente otros de estes padrones se han utilizado para estudiar el poblamiento: FERNÁNDEZ CORTIZO, Camilo, "«Aldeas y caserías a tiro de mano de piedra»: los asentamientos rurales en el arzobispado de Santiago (siglos XVI-XVIII)", Espacio, Tiempo y Forma, Serie IV, H. Moderna, t 7, (1994), 211-226; y RODRÍGUEZ FERNÁNDEZ, Delfina, "Aldeas y parroquias. La estructuración del territorio en la comarca celanovesa a lo largo de los tiempos modernos", en REBOREDA MORILLO, Susana (ed.), Homenaxe á profesora Lola F. Ferro: estudos de historia, arte e xeografía, Ourense, 2005, 536-555. Para una visión global de la época e la que se elaboró el padrón de San Clodio: EIRAS ROEL, Antonio (coord.), El reino de Galicia en la monarquía de Felipe II, Santiago de Compostela, 1998; y en particular sobre el mundo rural FERNÁNDEZ CORTIZO, Camilo "La Galicia rural en tiempos de Felipe", en Ibíd., 345-378.
} 
"JUNTOS EN UNA CASA DEBAJO DEL PODERÍO PATERNAL": LA FAMILIA EN LA

de la jurisdicción de San Clodio a finales del siglo XVI, según la metodología seguida por la bibliografía citada, permitirá añadir una pieza más al mencionado puzzle historiográfico; y aunque su información se reduzca a ese marco físico, corazón de la comarca vitícola del Ribeiro de Avia, el tamaño de la muestra (428 vecinos) parece suficiente para extraer las reflexiones que se irán desgranando a lo largo del texto, reflexiones que tal vez puedan ser extrapolables en diversos aspectos a todo el Ribeiro de Avia y con más cautelas a los Ribeiros ourensanos del Miño y del Arnoia.

\section{LAS FuENTES}

El padrón de San Clodio de 1580, fuente vertebradora de este trabajo ${ }^{5}$, forma parte de uno de los expedientes de desvinculación y venta de jurisdicciones eclesiásticas promovidos durante los reinados de Carlos I y Felipe II y autorizadas por sendas bulas papales que daban cobertura legal a un proceso con el que se pretendía contribuir a superar las dificultades presupuestarias ocasionadas por la costosa política exterior de estos monarcas. Para ello se iniciaron una serie de expedientes de investigación destinados a establecer el precio de venta de las jurisdicciones afectadas en los que se incluía la elaboración de un padrón para averiguar el número de vasallos de cada jurisdicción ${ }^{6}$. El de San Clodio se realizó entre los meses de julio y agosto de 1580 y los datos que aporta creemos que ofrecen un alto grado de fiabilidad. El hecho de que no sea propiamente una fuente fiscal es un elemento que de partida se la otorga, pero además la intervención conjunta en su confección de individuos con intereses encontrados hace razonable pensar que el resultado se debió ajustar bastante a la realidad: si el juez

\footnotetext{
5 Arquivo Histórico Provincial de Ourense (AHPOu). Mosteiro de Sta. M ${ }^{\mathrm{a}}$ de San Clodio, L. 696, fols. 391-457. Esta fuente ha sido transcrita y publicada con un estudio histórico y onomástico, si bien centrado en este último aspecto y sin abordar el estudio de las estructuras familiares: FERNÁNDEZ GONZÁLEZ, Frutos, O padrón de San Clodio de 1580. Estudo histórico e onomástico, Santiago de Compostela, 2008.

${ }^{6}$ Tras recibir la información del juez comisionado para realizar la valoración de los derechos jurisdiccionales y averiguar el número de vecinos de la jurisdicción, el Consejo de Hacienda ponía el precio y se iniciaban los trámites de la venta propiamente dicha. El proceso histórico de las ventas de señoríos eclesiásticos en la Corona de Castilla ha sido estudiado a fondo en FAYA DÍAZ, M ${ }^{a}$ Ángeles, "Los señoríos eclesiásticos gallegos y la venta de jurisdicciones en tiempos de Felipe II", en V Reunión Científica de la Asociación Española de Historia Moderna, Vol. 1, Cádiz, 1999, 101116. Véase también LÓPEZ DÍAZ, María, "Alteraciones en el mapa jurisdiccional gallego durante la Edad Moderna: las desmembraciones eclesiásticas del siglo XVI", Estudios Mindonienses, n 7, (1991), 559-588; SAAVEDRA, Pegerto, "Contribución al estudio del régimen señorial gallego"; Anuario de Historia del Derecho Español, nº 60, (1990), 103-184; y FERNÁNDEZ CORTIZO, Camilo, "El señorío rural gallego en tiempos de Felipe II" en EIRAS ROEL, Antonio (coord.), El reino, cit., 379-408. Para el caso de la jurisdicción de San Clodio véase FERNÁNDEZ GONZÁLEZ, Frutos, O padrón, cit., 34-40.
} 
comisionado por la Corona o los vecinos favorables a la venta ${ }^{7}$ hubieran intentado disminuir el número de vasallos, para minorar el valor de la jurisdicción, no lo habrían consentido los escribanos nombrados por el señor jurisdiccional, el Monasterio, al que habría de indemnizar la Corona en función del valor fijado en esta tasación. Además, el hecho de que se registren tanto las viudas como los pobres de solemnidad -infravalorados o ausentes en muchos vecindarios de época moderna-, o la insistencia de muchos asientos en explicitar que se declaran a todos los que viven bajo el mismo techo, parece despejar dudas al respecto de la confusión que se suscita en otras fuentes entre vecino real y vecino fiscal ${ }^{8}$.

Aldea por aldea y casa por casa se hizo una relación nominal de todos los individuos que convivían en cada hogar, de los cuales un pequeño número figuran como no residentes en la jurisdicción. Por tanto, cada asiento se corresponde con un núcleo corresidencial, es decir, un conjunto de individuos unidos o no por lazos familiares que viven bajo un mismo techo "juntos en una casa debajo del poderío paternal" -expresión que con distintas variantes aparece con frecuencia en el padrón-, y por eso en el grupo corresidencial se incluyen los criados, lo mismo que los contados casos de tutorandos y expósitos ${ }^{9}$. En general, el registro de cada vecino incluye una serie de datos normalizados: nombre, apellidos, estado civil, rango social y profesión del cabeza de familia y, en su caso, de la esposa, así como el nombre de los hijos. A diferencia de lo que ocurre habitualmente en este tipo de censos nominativos, en el caso de los viudos o de los casados en segundas nupcias figura siempre el nombre del o de la cónyuge difuntos y el de los hijos que quedaron de uniones anteriores, conyugales o no; y de la misma forma, se consignan siempre los hijos de las y los célibes. Por lo común, solamente se registran los vástagos residentes en cada hogar, pero a veces también se mencionan algunos que sirven como criados en otras casas o aquellos que ya han formado hogares neolocales. Además se consigna a los criados, generalmente con nombre y apellidos, y con frecuencia se indica su lugar de origen y el tiempo que lleva sirviendo en la casa. También se mencionan los expósitos y aquellos huérfanos que viven en casa de su tutor, y, si no es así, se apunta el nombre de este en

\footnotetext{
${ }^{7}$ Podemos suponer que algunos vasallos, por lo menos los de Lebosende, eran favorables a las ventas pues los de esa parroquia fueron los adjudicatarios de su propia jurisdicción.

${ }^{8}$ La problemática derivada del concepto de vecino fiscal ha sido tratada en SAAVEDRA FERNÁNDEZ Pegerto, Economía, cit., 50 y ss., y del mismo autor "Algúns problemas que presentan as fontes fiscais do século XVI do Arquivo Xeral de Simancas referidas a Galicia", en la monografía de su misma autoría A facenda Real na Galicia do Antigo Réxime, Santiago de Compostela, 1993, 17-37.

${ }^{9}$ La riqueza informativa de estos padrones ya había sido advertida, al respecto del padrón del coto del Balboa de 1584, en la antigua provincia de Mondoñedo por SAAVEDRA FERNÁNDEZ, Pegerto, Economía, cit., 125. Sobre el criterio de corresidencia en la definición de la comunidad familiar véase FLANDRIN, J-L., Orígenes de la familia moderna, Barcelona, 1979, 11 y ss.
} 
el registro en el que se asientan los tutorandos. Por último, se informa de la condición económica de muchos vecinos haciendo constar si tienen bienes en la jurisdicción o indicando si son pobres y si viven de la mendicidad.

Sin duda, la mayor carencia del padrón de 1580 es la omisión de las edades de los individuos ${ }^{10}$, lo que hurta la posibilidad de incorporar la variable temporal, que permitiría tener una visión dinámica del comportamiento de los hogares a lo largo de su ciclo vital. También deja en la penumbra, salvo en contadas ocasiones, aspectos del entramado familiar que rebasan el ámbito corresidencial, como redes de parentesco o prácticas de alianza; y no informa sobre la "familia" monástica de San Clodio (monjes, novicios, legos, criados ...), lo que habrá de tenerse en cuenta en los datos globales de población. En definitiva, el padrón refleja una imagen estática, propia de las fuentes censales; sin embago, pese a las deficiencias indicadas, posee una extraordinaria riqueza informativa, una riqueza que permitirá formarnos una imagen muy viva de la sociedad en esta jurisdicción del Ribeiro de Avia a finales del siglo XVI.

Algunos de sus silencios encuentran voz en el apeo de San Clodio y Cuñas de $1565^{11}$. Dada la condición de coto solariego que tenía la parroquia de Sta. María de San Clodio, en donde se ubicaba el Monasterio -toda ella era de dominio territorial del mismo- en este apeo aparecen todos los vecinos de esta feligresía con los bienes que tenían aforados a los monjes quince años antes de la realización del padrón. En cada declaración se hace una descripción pormenorizada de los bienes que lleva el declarante, incluyendo casas, viñas, huertas y montes también se dan casos en los que el declarante informa sobre bienes de distintos foros, normalmente de los que lleva por su parte y por la de su esposa-, de manera que es posible conocer, por ejemplo, el número de casas (80) o la extensión aproximada de la superficie agraria de la que disponía cada uno de los vecinos en la parroquia en una fecha relativamente próxima a la del padrón. La utilización de este apeo junto con otras fuentes, como el tumbo del Monasterio de San Clodio de $1607^{12}$ y los libros de bautizados y casados de la feligresía del mismo nombre $^{13}$, posibilitó encontrar referencias complementarias de casi todos los vecinos que aparecen en el padrón de esa parroquia, así como obtener datos económicos

\footnotetext{
10 Aunque la edad se indica de manera excepcional, acostumbran registrarse alusiones cualitativas a las mismas (mozo, moza, muchacho, mисhacha, niño, niña, pequeño, pequeña, viejo, vieja, niño de teta...) que siendo de interés son inservibles para la cuantificación.

11 AHPOu, Mosteiro de Sta. M ${ }^{\mathrm{a}}$ de San Clodio, L. 714. Sobre esta fuente véase LÓPEZ FERNÁNDEZ, Cesáreo, Fuentes para el estudio del Monasterio de San Clodio del Ribero de Avia. Apeos de 1565, Santiago de Compostela, 1976, (memoria de licenciatura inédita).

12 Archivo Histórico Nacional (AHN), Clero, Códice 424B.

13 Archivo Histórico Diocesano de Ourense (AHDO), Libros Sacramentales de la parroquia de San Clodio. Sign. 22-15-1-I.
} 
y demográficos que ayudan a interpretar la información del padrón de 1580 y que, a la vez, refuerzan su fiabilidad.

\section{LA JuRisdicción de SAN Clodio en 1580: ECONOMÍA Y POBLACiÓN.}

La familia rural del Antiguo Régimen, además de ser el ámbito en el que se desarrollaba la práctica totalidad de los aspectos de la vida del individuo, funcionaba como célula de reproducción demográfica y unidad de producción y consumo del sistema, así como principal vía de transmisión de los valores vertebradores de la comunidad ${ }^{14}$. En tanto que motor de una economía asentada sobre el sector primario, la familia rural no sólo estaba condicionada por las características estructurales de la sociedad en la que se incardinaba, sino que también era sensible a las coyunturas económico-demográficas de la misma. Por eso, para interpretar su comportamiento hay que tener presentes las particularidades del marco geográfico en el que se desarrolló cada modelo familiar, particularmente cuando se trata de un territorio de rasgos tan señalados como el Ribeiro de Avia, la principal comarca vitícola de Galicia desde época medieval. El papel fundamental del Monasterio de San Clodio - la abadía vitícola por excelencia de la provincia de Ourense- como agente articulador de la economía y sociedad de su entorno ${ }^{15}$, la gran productividad las tierras del Ribeiro y la rentabilidad del cultivo comercial del vino, principal exportación gallega desde la baja Edad Media, son, como veremos, elementos que ayudan a entender la fisonomía familiar de esta comarca ${ }^{16}$

\footnotetext{
${ }^{14}$ Como célula de reproducción social, biológica, y económica (unidad de reproducción y consumo), es definida en DUBERT GARCÍA, Isidro, Historia, cit., 12.

15 Una introducción a la historia del Monasterio de San Clodio en LUCAS ÁLVAREZ Manuel y LUCAS DOMÍNGUEZ, Pedro, El Monasterio de San Clodio do Ribeiro en la Edad Media: estudio y documentos, Sada-A Coruña, 1996; y en LÓPEZ FERNÁNDEZ, Cesáreo, Fuentes, cit.. Sobre el impacto económico de la colonización cisterciense en los siglos XII y XIII: PORTELA SILVA, Ermelindo, La colonización cisterciense en Galicia: (1142-1250), Santiago de Compostela, 1981.

${ }^{16}$ La economía vitícola gallega fue estudiada en la ya clásica monografía HUETZ DE LEMPS, A., Vignobles et vins du Nord-Ouest de l'Espagne, Burdeos, 1967 y desde la perspectiva de la Historia Moderna ha sido abordada por SAAVEDRA, Pegerto, "A economía vitícola na Galicia do Antigo Réxime", en Das casas, cit., 213-269. Sobre la exportación de vino del Ribeiro en la Edad Media FERREIRA PRIEGUE, Elisa, Galicia en el comercio marítimo medieval, A Coruña, 1988, 180. Sobre la importancia de las rentas vitícolas en el Monasterio de San Clodio, véase RIONEGRO FARIÑA, Isolina, La estructura económica del Císter orensano en la fase final del Antiguo Régimen, Ourense, 1998, 113-155.
} 
"JUNTOS EN UNA CASA DEBAJO DEL PODERÍO PATERNAL": LA FAMILIA EN LA JURISDICCIÓN DE SAN CLODIO DO RIBEIRO DE AVIA A FINALES DEL SIGLO XVI

Tabla 1. Vecinos, habitantes y densidad de población del núcleo jurisdiccional en 1580 y 1753

\begin{tabular}{lrrrrrrrrr}
\hline \multirow{2}{*}{ Parroquias } & \multirow{2}{*}{$\mathbf{K m}^{\mathbf{2}}$} & \multicolumn{3}{c}{ Padrón de 1580 } & \multicolumn{4}{c}{ Castastro de Ensenada, 1753 } \\
\cline { 2 - 10 } & & vec. & hab. & hab./vec. & hab/km & vec. & hab. & vec/hab & hab/km \\
\hline Bieite & 2,5 & 68 & 254 & 3,74 & 101,6 & 91 & 341 & 3,75 & 136,4 \\
\hline A Pena* & 0,8 & 27 & 80 & 2,96 & 100 & 31 & 119 & 3,84 & 148,75 \\
\hline Lebosende & 5,1 & 204 & 802 & 3,93 & 157,25 & 313 & 1213 & 3,88 & 237,84 \\
\hline San Clodio & 1,7 & 88 & 331 & 3,76 & 194,71 & 107 & 427 & 3,99 & 251,18 \\
\hline Total & $\mathbf{1 0 , 1}$ & $\mathbf{3 8 7}$ & $\mathbf{1 4 6 7}$ & $\mathbf{3 , 7 9}$ & $\mathbf{1 4 5 , 3}$ & $\mathbf{5 4 2}$ & $\mathbf{2 1 0 0}$ & $\mathbf{3 , 8 7}$ & $\mathbf{2 0 7 , 9 2}$ \\
\hline
\end{tabular}

Fuente: Padrón de San Clodio, AHPOu. Mosteiro de Sta. Ma de S. Clodio, L. 696; Catastro de Ensenada, AHPOu. Delegación Provincial de Hacienda de Orense, Libros: 2170, 2171, 2176, 2177, 2184, 2185.

* Datos relativos a los lugares de Cuñas y Cacabelos.

Tabla 2. Vecinos y habitantes en las pousas o granjas sobre las que el Monasterio tenía jurisdicción

\begin{tabular}{|c|c|c|c|c|c|c|}
\hline Pousa o granja & vec. & hab. & hab./vec & Parroquia & municipio actual & cultivos \\
\hline Cascalleira & 8 & 22 & 2,75 & Abelenda das Penas & Carballeda de Avia & \\
\hline Lamas de Santróns & 4 & 25 & 6,25 & Lamas & Cea & \\
\hline Santián & 2 & 9 & 4,50 & Amarante & \multirow{3}{*}{ Maside } & \multirow{3}{*}{ Tierras de pan } \\
\hline Figueiredo & 12 & 37 & 3,08 & Mafiside & & \\
\hline Toscaña & 2 & 6 & 3,00 & O Lago & & \\
\hline$\overline{\text { Eiras }}$ & 3 & 13 & 4,33 & Eiras & \multirow{3}{*}{ San Amaro } & \multirow{4}{*}{-Tierras de vino } \\
\hline Outeiro de Abades & 1 & 8 & 8,00 & Salamonde & & \\
\hline Outeiro & 4 & 15 & 3,75 & Navío & & \\
\hline Suiglesia & 5 & 17 & 3,40 & Gomariz & Leiro & \\
\hline TOTAL & 41 & 151 & 3,68 & & & \\
\hline
\end{tabular}

A la altura de 1580, el núcleo de la jurisdicción de San Clodio constituía un marco físico perfectamente definido y homogéneo emplazado en el superpoblado valle del Avia e integrado por las parroquias de Bieite, Lebosende y San Clodio, y una parte de la de San Lourenzo da Pena que comprendía los lugares de Cuñas y Cacabelos ${ }^{17}$ (véase tabla 1). Además, el Monasterio ejercía su señorío sobre una serie de enclaves separados de este núcleo jurisdiccional, las pousas o granjas, verdaderas islas jurisdiccionales dispersas por parroquias relativamente cercanas al Monasterio, algunas en tierras de vino y otras en las tierras de pan (véase

\footnotetext{
17 El valle del Avia se extiende desde ambos lados del cauce del río del mismo nombre en dirección norte-sur, a unos 80 metros de altitud, hasta, aproximadamente, la cima de las laderas de los montes que cierran el valle por el este y por el oeste, a una altitud de entre 300 y 400 metros. Las tres primeras parroquias se integran en el actual Ayuntamiento de Leiro y la de San Lourenzo da Pena en el de Cenlle.
} 
tabla 2) ${ }^{18}$. Desde mediados del siglo XII los monjes de San Clodio impulsaron la colonización y fomentaron el cultivo del vino en estas tierras, para lo cual fueron fijando población a través de distintos contratos agrarios entre los cuales se acabará imponiendo el foro. Se configuró en ese período la estructura agraria y el sistema de poblamiento que pervivirá durante toda la Edad Moderna ${ }^{19}$. De esta manera, la mayoría de los 33 barrios o aldeas que a finales del siglo XVI se documentan en el núcleo jurisdiccional ya existían en el siglo XIII, de modo que el despegue poblacional que se produjo en el siglo XVI se manifestó engrosando los antiguos núcleos, más que por creación de otros nuevos ${ }^{20}$. Estos 33 núcleos registran en 1580 una media próxima a los 12 vecinos, pero esta cifra oculta una gran diversidad de tamaños: mientras lugares como A Esperela o Agra no superaban los dos hogares, y otros, como Meín o Rubial, no llegaban a los diez -en muchos casos a estos pequeños núcleos apenas les distanciaban 50 o 100 metros $^{21}$-, existían localidades como Osebe o Vilaverde que rebasaban la treintena. En el total de la jurisdicción vivían 428 vecinos y 1618 habitantes, de los cuales residían en las granjas 41 familias y 151 individuos $^{22}$ (véase tabla 1 ). Por su

18 Las pousas de Vestiaría o Suiglesia de Gomariz y Outeiro de San Fiz estaban muy próximas a San Clodio; la de A Cascalleira a unos 10 kilómetros y las restantes, situadas en tierras de pan, en los denominados Chaos de Castela -la altiplanicie que a unos 400 metros de altitud separa los valles del Avia y el Barbantes- y en Cea, a una distancia del Monasterio de entre 10 y 15 kilómetros. El grupo de familias residentes en las tierras de pan no presentan características internas que las diferencien de las del conjunto de la jurisdicción, de ahí que no se hayan desechado de la muestra.

19 Fenómeno común a los territorios con implantación monástica: SAAVEDRA FERNÁNDEZ, Pegerto, Economía, cit., 20 y ss.; SOBRADO CORREA, Hortensio, Las tierras de Lugo en la Edad Moderna: economía campesina, familia y herencia, 1550-1860, A Coruña, 2001, 33 y ss.; FERNÁNDEZ CORTIZO, Camilo, "La Galicia, cit., 361-365.

20 También circunstancia común en Galicia: FERNÁNDEZ CORTIZO, Camilo, «Aldeas, cit.; SAAVEDRA, Pegerto, "O hábitat no noroeste peninsular nos ss. XVI-XIX”, en Espacios rurais $e$ sociedades campesiñas, Semata, Ciencias Sociais e Humanidades, Vol. 9, (1997), p.173-93. Sobre el poblamiento del Ribeiro de Avia RODRÍGUEZ RODRÍGUEZ, Juan M, "Evolución, estructura y principales caracteres de la población del Ribeiro de Avia", Cuadernos Feijonianos de Historia Moderna, $\mathrm{n}^{\circ}$ 1, (1999), 87-131. La relación completa de los lugares de la jurisdicción con su correspondiente número de vecinos en FERNÁNDEZ GONZÁLEZ, Frutos, O padrón, cit., 43.

21 Es el caso del centro de Lebosende, con cinco núcleos muy próximos a la Iglesia (A Costa, O Candendo, O Outeiro, O Corbal, A Raña), separados unos de otros por parcelas cultivadas. Y algo semejante ocurre en Bieite, donde la distancia entre los núcleos del centro de la parroquia (Souto y Torrón, Vale, Churide, Cima de Vila y Cabo de Vila) no supera los cien metros. La media de lugares por parroquia era de 10,3 con una media de 11,6 vecinos por núcleo. Para el conjunto de Galicia, se ha estimado que para esa época la media de lugares por parroquia fluctuaba entre 7,24 y 8,44, y la media de vecinos por aldea, entre 4,16 y 5,56. MARTÍNEZ RODRÍGUEZ, Enrique, "La población en la Galicia de Felipe II", en EIRAS ROEL, Antonio (coord.), El reino, cit., 441-472.

22 Se excluyeron del total contabilizado los miembros de las familias que aparecen asentadas en el padrón pero que no residen en la jurisdicción. Tampoco se incluyen los miembros de la comunidad conventual de San Clodio por no aparecer en el padrón, aunque sabemos que en 1584 en el Monasterio residían 24 monjes, si bien desconocemos el número de criados que los acompañaban. Datos extraídos de las Definiciones de los Capítulos Generales de la Congregación de Castilla. AHN, Manuscritos, 16536 y 16537. 
"JUNTOS EN UNA CASA DEBAJO DEL PODERÍO PATERNAL": LA FAMILIA EN LA

parte, el núcleo de la jurisdicción contaba con 387 vecinos y 1467 habitantes y abarcaba una superficie de unos $10 \mathrm{~km}^{2}$, de lo que resulta una densidad próxima a los $146 \mathrm{hab} / \mathrm{km}^{2}$, densidad que variaba entre un mínimo de $100 \mathrm{hab} / \mathrm{km}^{2}$, en la parte de la parroquia de San Lorenzo da Pena incluida en la jurisdicción, y un máximo de $195 \mathrm{hab} / \mathrm{km}^{2}$, en la feligresía de San Clodio. En este máximo influía, sin duda, la reciente formación del barrio de Ponte San Clodio, que tomaba su nombre del monumental puente construido por el Monasterio sobre el río Avia entre finales del siglo XV y principios del XVI, un núcleo donde se asentaron comerciantes y artesanos, atraídos por las ferias que allí se celebraban; para este barrio se documenta la primera casa en el año 1537, y gran cantidad de permisos para construir otras desde $1548^{23}$. Es decir, que la densidad de población del núcleo de la jurisdicción en 1580 ya superaba ampliamente los 100 hab $/ \mathrm{km}^{2}$, como también se desprende de los datos del censo de 1591 referidos a la jurisdicción de San Clodio $^{24}$. A pesar de que a este censo se le han señalado graves deficiencias para Galicia ${ }^{25}$, lo cierto es que presenta concordancia con las cifras del padrón de 1580 , ya que los 330 vecinos que suman los partidos de Lebosende, San Clodio más la aldea de Ibedo se ajustan bastante bien a los 387 vecinos que registra el núcleo de la jurisdicción en dicho padrón. La diferencia a la baja podría explicarla la naturaleza fiscal del censo de 1591, en el que es dudoso el cómputo de viudas (63 en el padrón) y pobres de solemnidad (7 en el padrón). Por el contrario, los datos del denominado censo de los obispos de 1587, que registra un $39 \%$ menos de vecinos en el conjunto de las parroquias de San Clodio, Bieite y Lebosende ${ }^{26}$, ponen de manifiesto sus deficiencias para el territorio que nos ocupa, señaladas también para el conjunto de Galicia ${ }^{27}$. Pero, con independencia de la valoración que merezca cada una de estas fuentes, todas revelan que el milagro poblacional del Ribeiro era una realidad a finales del siglo $\mathrm{XVI}^{28}$, sobre todo si se compara su densidad de po-

\footnotetext{
23 AHN, Códice 424B. Véase el tumbo de la parroquia de San Clodio dentro del códice.

${ }^{24}$ Se pueden calcular los habitantes aplicándole al número de vecinos de 1591 el índice de conversión 3,78 que resulta del Padrón de 1580. En el partido de San Cloyo de Ribero de Abia y aldea de Ybedo (que entendemos que engloba a la parroquia de San Clodio, la parroquia de Bieite y los barrios de Cuñas y Cacabelos) se declaran 172 vecinos pecheros y en el partido de Lebosende 158 (que coincidiría con la parroquia del mismo nombre) 158 vecinos de igual calidad. Censo de la población de las provincias y partidos de la Corona de Castilla en el siglo XVI, Madrid, 1829. 35-37.

25 EIRAS ROEL, Antonio, La población de Galicia, 1700-1860. Crecimiento, distribución espacial y estructura de la población de Galicia en los siglos XVIII y XIX, Santiago de Compostela, 1996, 25-27; SAAVEDRA FERNÁNDEZ, Pegerto, Economía, 51-3; MARTÍNEZ RODRÍGUEZ, Enrique, "La población, 443.

26 Censo de la población, 275: en San Clodio 34 vecinos, en Lebosende 150 y en Bieite 36.

27 Sobre las deficiencias del censo de 1587 véase MARTÍNEZ RODRÍGUEZ, Enrique, "La población, cit., 443.

${ }^{28}$ Sobre demografía del Ribeiro véase RODRÍGUEZ RODRÍGUEZ, Juan Manuel, "Evolución, cit..
} 
blación con los 21 o 22 hab $/ \mathrm{km}^{2}$ que se estiman para el Reino de Galicia en 1591 o los $18 \mathrm{hab} / \mathrm{km}^{2}$ para la Corona de Castilla en la misma fecha, territorios para los que buena parte del siglo XVI también había sido una etapa de expansión económica y demográfica, lo mismo que para todo el occidente europeo ${ }^{29}$.

Resulta difícil concretar con exactitud el momento de arranque de este ímpetu demográfico inyectado por la economía del vino, si bien ciertos datos pueden ayudar a encontrar alguna respuesta que, aunque parcial, resulte razonable. Centrándonos en Sta. Ma . de San Clodio -la parroquia de la que más información disponemos y cuyas datos quizá pudiesen extrapolarse al total del núcleo jurisdiccional-, se observa que el número de contratos de foro otorgados por el Monasterio en la misma crece de forma espectacular durante el siglo XVI con respecto a los siglos precedentes ${ }^{30}$; esto debería ir acompañado, en buena lógica, de un importante incremento poblacional. En la misma dirección apuntan los datos aportados por $\mathrm{M}^{\mathrm{a}}$ Angeles Faya, extraídos de las informaciones recabadas para las ventas jurisdiccionales realizadas al amparo de la bula de 1551 y en las que se documenta el número de vasallos de las instituciones monásticas gallegas en 1552. De ser correctas estas cifras -San Clodio aparece con 344 vasallos, de los que 243 pertenecían al núcleo de la jurisdicción $^{31}$-, estaríamos ante un espectacular crecimiento poblacional de casi el $60 \%$ en apenas treinta años. Aunque tal aumento pueda parecer inadmisible, lo cierto es que el incremento del número de foros otorgados por el Monasterio señala un fortísimo crecimiento demográfico, y en base a ello hay que suponer que el milagro poblacional se extendió a todo el siglo $\mathrm{XVI}^{32}$. Es evidente que tal incremento no pudo

29 MARTÍNEZ RODRÍGUEZ, Enrique, "La población, 447, 450-3; FERNÁNDEZ CORTIZO, Camilo, "La Galicia, cit., 346 y ss.

${ }^{30}$ En el tumbo del Monasterio de 1607 se registran para la parroquia de San Clodio 16 nuevos foros en el siglo XIV y 17 en el XV, cifras parecidas registran las parroquias de Lebosende y Bieite para los mismos períodos. Sin embargo, solamente en la primera década del XVI se registran 17 foros, los mismos que en todo el siglo anterior. En la primera mitad de este siglo el número de foros se eleva a 73 , y en la segunda a 115 , aunque en este último dato habría que tener en cuenta que entre 1595 y 1596 se renovaron buena parte de los foros de la parroquia. Tumbo del Monasterio de San Clodio de 1607. AHN. Clero, 424B. La proliferación de contratos agrarios y roturación de nuevas tierras durante el siglo XVI en relación con la expansión demográfica es un fenómeno documentado para la generalidad de Galicia: SAAVEDRA FERNÁNDEZ, Pegerto, Economía, cit., 64-65; GELABERT GONZÁLEZ Juan E., Santiago, cit., 47, 95-99; SOBRADO CORREA, Hortensio, Las tierras, cit., 33 y ss.; SAAVEDRA, Pegerto, Galicia. Historia. Tomo III. La Galicia del Antiguo Régimen. Economía y sociedad. A Coruña, 1991, 52 y ss.

${ }^{31}$ Se documentan 61 vecinos en San Clodio y Cuñas; 47 en Bieite y 135 en Lebosende: FAYA DÍAZ, Ma Ángeles, "Jurisdicciones de los monasterios cistercienses gallegos a mediados del S.XVI" en Actas Congreso Internacional sobre San Bernardo e o Cister en Galicia e Portugal, Ourense, 1992, Vol. 1, 289-308.

32 En la segunda mitad del siglo el número de contratos de foro aumentó en un $157 \%$ respecto a la primera mitad, mientras en esa primera mitad el número de contratos fue el $429 \%$ de todos los otorgados en el siglo XV. 
"JUNTOS EN UNA CASA DEBAJO DEL PODERÍO PATERNAL": LA FAMILIA EN LA

deberse únicamente a un fecundo saldo vegetativo, sino que estas parroquias hubieron de ser polo de atracción de nuevos pobladores atraídos por una coyuntura económica favorable en la que el Monasterio ejerció un papel fomentador, no sólo en lo que respecta a la economía del vino, sino también con la promoción de importantes obras en los edificios del Monasterio o el mencionado puente sobre el Avia $^{33}$. Por otra parte, parece que la emigración masculina definitiva, aunque estaba presente, aun no era demasiado intensa en 1580, a tenor de la relación de masculinidad que se observa (93,1 hombres por cada 100 mujeres) y del reducido número de varones casados ausentes ${ }^{34}$; de modo que la movilidad geográfica era, en su mayoría, intraparroquial o entre feligresías más o menos cercanas ${ }^{35}$.

\section{TAMAÑO Y COMPOSICIÓN INTERNA DE LAS FAMILIAS}

El tamaño medio de las familias empadronadas en 1580 (3,78 individuos/hogar), se sitúa por debajo de la media conocida para Galicia (4,4 individuos/hogar) o la provincia de Ourense $(4,15)$ a mediados del siglo XVIII y muestra un franco contraste con las amplias familias lucenses ${ }^{36}$. Sin embargo, la cifra se encuentra próxima a las

\footnotetext{
33 Sobre el origen foráneo de muchas familias de la jurisdicción de San Clodio detectado a partir de los complementos onomásticos véase FERNÁNDEZ GOZÁLEZ, Frutos, O padrón, cit.. Noticias sobre las obras y el estado del Monasterio en el siglo XVI pueden encontrase en: FERNÁNDEZ GONZÁLEZ, Frutos, "Aproximación al Abadologio del Monasterio de San Clodio do Ribeiro", en Actas III Congreso Internacional sobre el Cister en Galicia y Portugal, Vol. I, Ourense, 2006, 95-121.

${ }^{34}$ En los casos de este tipo no se expresa su paradero y tan sólo se indica el tiempo aproximado de ausencia. Salvo un marido que se ausentó hace más de veinte años, los seis restantes se mueven en periodos que van de tres a seis años, lo que podría ser emigración temporal que en parte o en todos los casos podría derivar en definitiva.

35 A partir de distintas menciones de movilidad geográfica reseñadas en el padrón de 1580 (familias que conservando casa y hacienda en la jurisdicción ya no están avencindadas en esta, hijos emancipados tras el matrimonio o por entrar a servir como criados) se calcula a partir de los 100 destinos concretados, que 71 son lugares de la jurisdicción de San Clodio, seguidos a mucha distancia por localidades del noroeste ourensano (15\%) -condado Ribadavia y localidades de los actuales municipios de Avión, Beade, Carballeda de Avia, O Carballiño, Leiro, Ourense y Oseira- y por cinco casos en el territorio de la actual provincia de A Coruña (Santiago de Compostela, A Coruña y Touro), cuatro fuera de Galicia, dos de ellos concretan que están en Castilla, y cinco casos en localidades que no se han podido identificar.

${ }^{36}$ El dato global para Galicia en DUBERT GARCÍA, Isidro, Historia, cit., 83; y para la provincia de Ourense: SAAVEDRA, Pegerto, Das casas, cit., 22. A mediados del siglo XVIII, el tamaño medio era de 4,12 en Celanova (RODRÍGUEZ FERNÁNDEZ, Delfina, A terra e as xentes. Nacer, vivir e morrer na comarca de Celanova ó longo da Idade Moderna, A Coruña, 1999, 130), de 4,9 en Cea (LÓPEZ ÁLVAREZ, Ma José, A terra de Cea no antigo réxime. Formas de vida nunha comarca de transición ourensá, Ourense, 2007, 193), de 4,18 hab./hogar en Monterrei y Alta Limia, (GONZÁLEZ ABELLÁS, Isaac César, La comarca de Monterrei en el Antiguo Régimen. Economía, demografía y familia, Santiago de Compostela, 2010, 129; FERREIRO PÉREZ, Rosa, La Alta Limia en los siglos XVII y XVIII. Muestreo parroquial, Santiago, 1981, [memoria de licenciatura inédita], 30) y de 5,28 en el interior de Lugo (SOBRADO CORREA, Hortensio, Las tierras, cit., 84).
} 
que se obtienen del Catastro de Ensenada para las tres parroquias que conformaban el núcleo jurisdiccional de San Clodio $(3,85)$, para toda la comarca del Ribeiro de Avia $(3,96)$ y para el litoral gallego ${ }^{37}$. Como es natural, esta media oculta diversidad de tamaños sin que se observe una clara concentración de hogares de unas determinadas dimensiones (véase tabla 3). Por el contrario, la proporción es bastante equilibrada entre los fuegos de dos a cuatro miembros, que en conjunto suman algo más de la mitad del total (55,38\%), y revela una alta proporción de solitarios/as (14,25\%), como también se observa en otras comarcas ourensanas a mediados del XVIII ${ }^{38}$. Los hogares de cinco miembros se aproximan al $12 \%$ y los de seis o más individuos se mueven por debajo del 6,5\%, en proporción descendente conforme aumenta el tamaño de los hogares. Más clara se percibe la concentración de individuos en los hogares de 3 a 5 miembros que, en conjunto, reúnen a la mitad de la población (véase gráfico 1).

Tabla 3. Tamaño de los hogares en la jurisdicción de San Clodio en 1580

\begin{tabular}{lllll}
\hline Número de & \multicolumn{2}{l}{ hogares } & \multicolumn{2}{l}{ individuos } \\
miembros & $\mathbf{n}^{\mathbf{0}}$ & $\mathbf{\%}$ & $\mathbf{n}^{\mathbf{0}}$ & $\mathbf{\%}$ \\
\hline $\mathbf{1}$ & 61 & 14,25 & 61 & 3,77 \\
\hline $\mathbf{2}$ & 76 & 17,76 & 152 & 9,39 \\
\hline $\mathbf{3}$ & 85 & 19,86 & 255 & 15,76 \\
\hline $\mathbf{4}$ & 76 & 17,76 & 304 & 18,79 \\
\hline $\mathbf{5}$ & 49 & 11,45 & 245 & 15,14 \\
\hline $\mathbf{6}$ & 28 & 6,54 & 168 & 10,38 \\
\hline $\mathbf{7}$ & 22 & 5,14 & 154 & 9,52 \\
\hline $\mathbf{8}$ & 12 & 2,80 & 96 & 5,93 \\
\hline $\mathbf{9}$ & 13 & 3,04 & 117 & 7,23 \\
\hline $\mathbf{1 0}$ a 12 & 6 & 1,40 & 66 & 4,08 \\
\hline Total & 428 & 100 & 1618 & 100,00 \\
\hline
\end{tabular}

Gráfico 1. Hogares e individuos que los integran según el tamaño de la familia

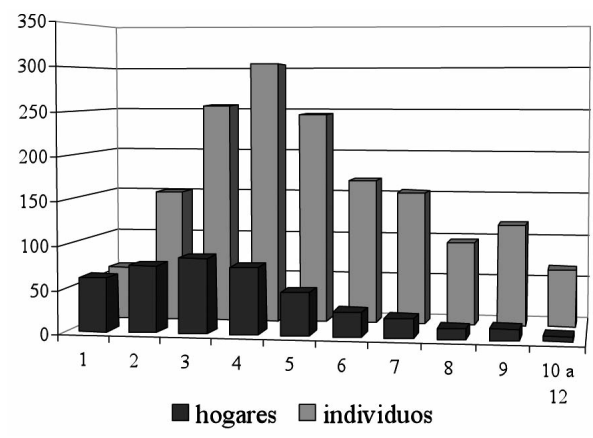

Fuente: Padrón de San Clodio, AHPOu. Mosteiro de Sta. Mª de S. Clodio, L. 696.

\footnotetext{
${ }^{37}$ Las cifas de San Clodio son elaboración propia a partir de los libros personales de Sta. M $\mathrm{M}^{\mathrm{a}}$ de S. Clodio, Sto. Adrao de Bieite y S. Miguel de Lebosende del Catastro de Ensenada de 1753; AHPOu, Delegación Provincial de Hacienda de Orense, libros 2170, 2171, 2176, 2177, 2184, 2185. En la tabla 1 la cifra de vecinos del coto de Cuñas procede del Interrogatorio accesible en [http://pares.mcu.es/Catastro/servlets/ServletController] (no se conserva el personal de legos en el AHPOu) y la de habitantes resulta de aplicarle el índice de conversión del conjunto de las restanes parroquias. El dato del Ribeiro de Avia, referido a 18 parroquias en RODRÍGUEZ RODRÍGUEZ, Juan M., "Evolución, cit., 89. En la península del Salnés los hogares contaban con una media de 3,8 miembros (PÉREZ GARCÍA, José Manuel, Un modelo de sociedad rural de Antiguo Régimen en la Galicia costera: la Península del Salnés [Jurisdicción de La Lanzada], Santiago de Compostela, 1979, 76) y con una media de 3,97 en la Costa da Morte a mediados del siglo XVIII (CASTIÑEIRA CASTRO, Víctor. M., "O fogar no extremo occidental da Costa da Morte [1750-1850]" en Historia Nova VI e VII: Contribución dos Xoves Historiadores de Galicia, Santiago, 1999, 145-167)

38 RODRÍGUEZ FERNÁNDEZ, Delfina, A terra, cit., 133.
} 
"JUNTOS EN UNA CASA DEBAJO DEL PODERÍO PATERNAL": LA FAMILIA EN LA

Como es sabido, las características asociadas al, o a la, cabeza de familia, como el sexo y estado civil, condicionaban la fisonomía del agregado doméstico, de manera que los hogares regidos por mujeres eran habitualmente de menor tamaño, si bien tanto el tamaño de sus familias como el peso porcentual de este grupo variaba según la zona de Galicia de la que se tratase. En el caso de la jurisdicción de San Clodio uno de cada cuatro hogares de 1580 (24,77\%) era de este tipo, cifra próxima a la que registra el núcleo de la jurisdicción a mediados del siglo XVIII (25,91\%), y claramente superior a la que se conoce para el conjunto de Galicia en esta última fecha $(19,20 \%)^{39}$ (véase tabla 2). En realidad, la elevada presencia de hogares femeninos es una nota característica de la provincia de Ourense, bien documentada para mediados del siglo XVIII, y que contrasta abiertamente con el caso del interior lucense, donde las jefaturas femeninas raramente superaban el 10\%, en la misma fecha. Todo ello apunta hacia una mayor relevancia del rol femenino en las comunidades rurales ourensanas, circunstancia que Pegerto Saavedra ha relacionado con las diferentes prácticas hereditarias en uno y otro lugar ${ }^{40}$. En el San Clodio de 1580 , las jefas de casa eran en su mayoría viudas $(17,29 \%)$, en mucha menor medida solteras $(5,84 \%)$, y excepcionalmente casadas $(1,64 \%)$, ya que estas últimas sólo administran el hogar en ausencia prolongada de sus maridos ${ }^{41}$. Pero no sólo era la ausencia del cónyuge lo que hacía más pequeños a los hogares femeninos, sino también un menor número de hijos -téngase en cuenta la superior proporción de célibes entre las jefaturas femeninas- y, sobre todo, de criados. Esta discreta presencia de prole y servicio doméstico parece indicativa de un soporte económico más precario, que obligaría a una parte de los vástagos de estas mujeres a engrosar como criados otras casas de economía

39 En 1753, en los libros personales de legos del Catastro de Ensenada de las parroquias de Bieite, Lebosende y San Clodio se documentan 128 jefaturas femeninas entre un total de 494 vecinos legos (véase nota 37). Para el conjunto de la Galicia DUBERT GARCÍA, Isidro, Historia, cit., 61.

${ }^{40}$ En distintas comarcas ourensanas las jefaturas femeninas se situaban por encima del $20 \%$ a mediados del XVIII: 23,80\% en Celanova (RODRÍGUEZ FERNÁNDEZ, Delfina, A terra, cit., 131), 21,10\% en Cea (LÓPEZ ÁLVAREZ, Ma José, A terra, cit., 180), y 21,6\% en Monterrei (GONZÁLEZ ABELLÁS, Isaac César, La comarca, cit., 131). En el siglo XVI en la diócesis de Lugo, entre el 3,2\% y el 10,7\% (SAAVEDRA, Pegerto, La vida cotidiana en la Galicia del Antiguo Régimen, Barcelona, 1994, 162). En el interior de Lugo a mediados del XVIII 10\% (SOBRADO CORREA, Las tierras, cit., 72). Sobre el diferente rol de la mujer ourensana véase SAAVEDRA, Pegerto, Das casas, cit., 29 y 261. El coetáneo padrón del coto mindoniense de Balboa de 1584, presenta un $28,94 \%$ de hogares femeninos sobre un total de 38 familias. SAAVEDRA FERNÁNDEZ, Pegerto, Economía, cit., 125. Una completa visión de los hogares femeninos en toda Galicia en REY CASTELAO, Ofelia, y RIAL GARCÍA, Serrana, Historia de las mujeres en Galicia. Siglos XVI al XIX, Vigo, 2009, 65 y ss.

${ }^{41}$ Estas cifras se aproximan a las calculadas por P. Saavedra para el Ribeiro (14\% de hogares regidos por viudas y 8,9\% por solteras): SAAVEDRA, Pegerto, Das casas, cit., 29. 
más saneada ${ }^{42}$. Las jefaturas a cargo de viudas quintuplican a las de los hogares regidos por varones del mismo estado civil, lo que no sólo se debería a la más temprana edad de defunción de los individuos del género masculino, sino también a una mayor facilidad de los viudos para volver a casarse. Tal y como revela el padrón de 1580, los hombres casados más de una vez (12,07\% del total de varones casados y viudos) son casi el doble de las mujeres en las mismas circunstancias $(7,02 \% \text { del total de mujeres casadas o viudas })^{43}$.

Tabla 4. Tamaño y composición interna de los hogares según el sexo y estado civil de los cabezas de familia

\begin{tabular}{lrrrrrrrrrr}
\hline Estado civil & \multicolumn{3}{c}{$\mathbf{n}^{\mathbf{0}}$ \% cónyug. hijos } & nietos & ascend. colater. otros criados $\begin{array}{r}\text { tamaño } \\
\text { familia }\end{array}$ \\
\hline soltera & 25 & 5,84 & $* *$ & 0,48 & $* *$ & $* *$ & 0,20 & $* *$ & $* *$ & 1,68 \\
\hline casada & 7 & 1,64 & $* *$ & 0,86 & $* *$ & $* *$ & $* *$ & $* *$ & $* *$ & 1,86 \\
\hline viuda & 74 & 17,29 & $* *$ & 1,42 & 0,04 & $* *$ & $* *$ & $* *$ & 0,23 & 2,69 \\
\hline total mujeres & $\mathbf{1 0 6}$ & $\mathbf{2 4 , 7 7}$ & $* *$ & $\mathbf{1 , 1 6}$ & $\mathbf{0 , 0 3}$ & $* *$ & $\mathbf{0 , 0 5}$ & $* *$ & $\mathbf{0 , 1 6}$ & $\mathbf{2 , 4 0}$ \\
\hline soltero & 32 & 7,48 & $* *$ & 0,09 & $* *$ & $* *$ & 0,34 & 0,03 & 0,19 & 1,66 \\
\hline casado & 275 & 64,25 & 1,00 & 2,03 & 0,03 & 0,004 & 0,01 & 0,04 & 0,50 & 4,61 \\
\hline viudo & 15 & 3,50 & $* *$ & 1,60 & $* *$ & $* *$ & $* *$ & $* *$ & 0,20 & 2,80 \\
\hline total hombres & 322 & 75,23 & 0,85 & 1,82 & 0,02 & 0,003 & 0,04 & 0,04 & 0,46 & 4,24 \\
\hline TOTAL & $\mathbf{4 2 8}$ & $\mathbf{1 0 0 , 0 0}$ & $\mathbf{0 , 6 4}$ & $\mathbf{1 , 6 6}$ & $\mathbf{0 , 0 3}$ & $\mathbf{0 , 0 0 2}$ & $\mathbf{0 , 0 5}$ & $\mathbf{0 , 0 3}$ & $\mathbf{0 , 3 8}$ & $\mathbf{3 , 7 8}$ \\
\hline $\mathbf{N}^{\mathbf{0}}$ indivíduos & 428 & & 275 & 709 & 11 & 1 & 18 & 12 & 164 & 1618 \\
\hline \% individuos & 26,45 & & 17,00 & 43,82 & 0,68 & 0,06 & 1,11 & 0,74 & 10,14 & 100,00 \\
\hline
\end{tabular}

Fuente: Padrón de San Clodio, AHPOu. Mosteiro de Sta. M ${ }^{\text {a }}$ de S. Clodio, L. 696. * "otros" incluye a tutorandos y expósitos. **Para mayor claridad se omiten los valores que equivalen a cero absoluto.

42 El asiento número 39 de Lebosende es bien elocuente: "Maria do Canpo esta casada con Nycolas Fernández, el qual se fue desta tierra podra aver quatro años y no se sabe del y la dicha Maria do Canpo bibe sola y padece arta necesidad y mucha pobreza. Tiene una hija que se llama Polonia Fernández, criada de Pedro de Caldas, anotado en el capitulo precedente", FERNÁNDEZ GONZÁLEZ, Frutos, O padrón, cit. 178.

${ }^{43}$ Del total de 646 individuos -varones y mujeres, fueran o no jefas de casa- que se casaron alguna vez, el 9,29\% lo hicieron dos o más veces, si bien sólo se registran dos hombres y una mujer que celebraron un tercer matrimonio. H. Sobrado considera escasa la incidencia de las segundas nupcias para el conjunto de Galicia (SOBRADO CORREA, Hortensio, A Galicia, cit., 88), aunque su presencia fue desigual en la Galicia del siglo XVIII: sobre el 10\% en las áreas costeras, Tierra de Montes y Caldevergazo; en Xallas, Bergantiños, Mahía proporciones que superan el 20\% y aún el 30\% en la cuenca media del Ulla y entorno compostelano, apreciándose cierto descenso en la última parte del XVIII (citamos por REY CASTELAO, Ofelia, "Mecanismos reguladores de la nupcialidad en la Galicia atlántica. El matrimonio a trueque", en Obradoiro de Historia Moderna: homenaje al profesor Antonio Eiras Roel en el XXV aniversario de su cátedra, 1990, 247-268). Sobre la mayor incidencia de las segundas nupcias entre los varones véase PEREZ GARCÍA, José Manuel, Un modelo, cit., 72. 
Por lo común, los hogares de jefatura masculina estaban regidos por casados $(64,25 \%)$, siendo muy pocos los viudos $(3,50 \%)$-por los efectos, ya citados, de una edad de defunción más temprana de los varones y una mayor facilidad para contraer segundas nupcias-, y todavía menos los solteros $(1,66 \%)$ que ejercían de cabezas de casa. Las dimensiones medias de sus respectivas familias también seguía este orden decreciente: los casados presentan un tamaño medio de 4,61 individuos/hogar, los viudos de 2,80 y los solteros de 1,66. El mayor tamaño de los hogares de casados, incluso por encima de la media global de la jurisdicción, se debe, no sólo a la presencia universal de la esposa, sino a los mayores aportes de hijos $(2,03)$ y criados $(0,50)$. Esta circunstancia es particularmente acusada en los hogares regidos por varones casados más de una vez, que presentan un tamaño $(5,94)$ muy superior a la media global $(3,78)$. Esto se debe a un mayor aporte de prole $(2,73)$ y, sobre todo, de criados $(0,97)$, lo que parece indicativo de una base económica más sólida.

Entre los distintos miembros que conforman los hogares -salvo en los regidos por varones solteros-, el aporte de hijos es siempre el más importante en todos los tipos de familia que acabamos de ver y se trata de un componente humano fundamental en las economías domésticas del rural (véase tabla 4): la media global de la jurisdicción es de 1,66 hijos/hogar, están presentes en el $68 \%$ de las familias y representan cerca del $44 \%$ de la población. Pese al predominio aplastante de los hogares de estructura nuclear en la jurisdicción de San Clodio, la presencia de los hijos en el conjunto de las familias se encuentra por debajo de las cifras conocidas para la Galicia de mediados del siglo XVIII ${ }^{44}$. Esto, como veremos, lo explica el importante peso que alcanzan en esta jurisdicción los hogares de solitarios y de parejas conyugales sin hijos, ya que, si se aíslan las familias con descendencia, la presencia de esta asciende a 2,44 hijos/hogar y si se hace lo mismo con los matrimonios con hijos su peso se sitúa en 2,57 hijos/hogar ${ }^{45}$. El equilibrio intersexual que se documenta, ligeramente favorable a los varones $(51,34 \%$ de hijos varones, relación de masculinidad del 105,51), parece revelar un leve subregistro de hijas ${ }^{46}$. Aun así, no debe descartarse que en este hecho también pueda incidir en alguna medida el desequilibrio favorable a los varones al nacer, toda vez que varios indicios parecen apuntar a que la edad media de la descendencia no es muy elevada debido a un temprano abandono del hogar paterno, ya sea para casarse o para servir como criados en otros hogares. La inmensa mayoría de familias con hijos $(78,36 \%)$ no cuentan con más de tres en su seno y sólo el 12,71\% de las mismas

\footnotetext{
44 1,91 hijos/hogar, que suponían el 43,4\% de la población y estaban presentes en el $72 \%$ de las familias (DUBERT GARCÍA, Isidro, Historia, cit., 65).

45 En la Galicia de mediados del XVIII 2,32 hijos/matrimonio: Ibíd.

46 Dubert observa en el Catastro de Ensenada subregistro de hijas (55\% de hijos varones) Ibíd.
} 
declaran cinco o más vástagos ${ }^{47}$; lo que no sólo está relacionado con una mayor o menor fecundidad, sino que es el resultado de la combinación de los distintos factores que condicionan la permanencia de la descendencia en sus hogares de origen $^{48}$.

Dado que el padrón de 1580 indica cuantos hijos son de la pareja conyugal y cuales proceden de uniones anteriores, tanto de la madre como del padre, sabemos que algo más de uno de cada diez hijos declarados $(11,14 \%)$ procedían de relaciones anteriores, mayoritariamente de uniones conyugales $(7,90 \%)$, pero también extramaritales $(3,24 \%)$. Los descendientes aportados por el cónyuge varón duplican ampliamente a los de las mujeres (7,62\% frente a 3,39\%), debido a la mencionada mayor facilidad de los primeros para contraer segundas nupcias y sucesivas, y, por lo mismo, son más habituales los hijos de soltera $(1,27 \%)$ que viven con su madre que los que están bajo la custodia de un padre célibe, circunstancia muy excepcional ( $0,56 \%$ del total de hijos). En ocasiones, los padres también declaran a los hijos "bastardos", aunque estén bajo la custodia de la madre o sirviendo a soldada. Esta circunstancia, junto al hecho de que algunas casadas declaren hijos fruto de relaciones extramatrimoniales anteriores, no sólo revela una significativa presencia de la "ilegitimidad", sino también la mayor tolerancia social que, a este respecto, existía en Galicia en comparación con otras regiones ${ }^{49}$. En suma, en el hogar podían convivir hermanastros fruto de sucesivas nupcias, así como descendencia habida fuera del matrimonio, pero la permanencia en estos hogares no siempre debió ser factible para los hijos de las primeras uniones. Así lo parecen revelar algunos registros en los que se documenta el abandono del hogar por parte de estos ${ }^{50}$ y es una de las razones que llevan a Pegerto Saavedra a percibir en el padrón de 1584 del coto de Balboa "estructuras familiares poco consistentes por estas fechas" ${ }^{\text {" } 1 . ~ P o r ~ l o ~ q u e ~ r e s p e c t a ~ a ~ a s c e n d e n t e s ~ y ~}$ colaterales, su presencia es anecdótica: tan sólo se registra una madre conviviendo dentro de un núcleo extenso, lo que sumado a la reducida presencia de hermanos,

\footnotetext{
$4732,99 \%$ de hogares con 1 hijo, 31,27\% con 2 hijos, $14,43 \%$ con 3 hijos, $8,59 \%$ con 4 hijos, 7,56\% con 5 hijos, 3,44\% con 6 hijos, y 1,72\% con 7 hijos. En el conjunto de Galicia a mediados del XVIII, el $54 \%$ de las familias tienen 2 o más hijos, mientras que un 23,9\% superan los cuatro, Ibíd. 48 Ibíd., 66.

49 Este es un fenómeno bien conocido, particularmente acusado en la provincia de Lugo: SAAVEDRA, Pegerto, Das casas, cit., 53-60. A este respecto véase también PÉREZ GARCÍA, José Manuel, Un modelo, cit., 111-3.

${ }^{50}$ Entre otros asientos, parece indicativo de esto el no 88 de Lebosende: "Rodrigo da Raña ... es tutor de Amaro del Chao y Gerónimo y Sabina, todos hermanos hijos que quedaron de Pedro del Chao, el moço, difunto, ... y Maria da Pena, su muger, que agora lo es de Lorenço da Pena ... pero estos menores no tienen bienes por que les fueron tomados por deudas y acreedores de sus padres y cada uno destos menores anda por su cabo y no se sabe donde estan". Casos similares se dan en los registros 60 y 80 de Lebosende. FERNÁNDEZ GONZÁLEZ, Frutos, El padrón, cit., 182, 185-6.

51 SAAVEDRA FERNÁNDEZ, Pegerto, Economía, cit., 125.
} 
"JUNTOS EN UNA CASA DEBAJO DEL PODERÍO PATERNAL": LA FAMILIA EN LA

cuñados y sobrinos -en varios casos en calidad de criados- no alcanza el $1 \%$ de los individuos empadronados. Por último, tienen una presencia todavía más insubstancial una serie de corresidentes sin lazos familiares declarados con el cabeza de casa; es el caso de los expósitos y los menores huérfanos tutelados, aunque en este último caso pudieran presumirse lazos familiares o sistemas de alianza que no se desvelan ${ }^{52}$.

Caso bien distinto al de los expósitos y menores huérfanos es el del servicio doméstico, otro aporte corresidencial (0,38 individuos/hogar) sin lazos familiares -salvo las excepciones mencionadas- que en el padrón de 1580 supera nada menos que el 10\% de la población y está presente en el $23 \%$ de los hogares. Estas magnitudes, la riqueza informativa que al respecto aporta el padrón y la importancia que, de por si, tuvo el servicio doméstico en las sociedades rurales del Antiguo Régimen como complemento de fuerza de trabajo en los procesos productivos, obliga a realizar un análisis algo más detenido. Las cifras de criados inscritos en el padrón de San Clodio de 1580 se aproximan a las documentadas en la Europa Noroccidental en la Edad Moderna y duplican a las correspondientes al conjunto de Galicia a mediados del siglo XVIII, que solamente alcanzaban los 0,15 criados por hogar, estaban presentes en un 10,7\% de los mismos y suponían el 3,4\% de la población ${ }^{53}$. El reparto intersexual que se registra en San Clodio es favorable al segmento femenino $(55,5 \%)$, dato muy parecido al que se documenta para Galicia a mediados del siglo XVIII $(56,9 \%)$, si bien en esta fecha la feminización del servicio doméstico era mucho más marcada en algunas comarcas ourensanas y, desde luego, en el ámbito urbano ${ }^{54}$.

\footnotetext{
52 Sobre tutela, familia e infancia véase DUBERT GARCÍA, Isidro, Historia, cit., 241-250.

53 Ibíd., 75. Ese peso era superior en el interior de Lugo, donde se registra una media de 0,3 criados por vecino, que suman el 4,7\% de la población y están presentes en el $21,7 \%$ de los hogares (SOBRADO CORREA, H. Las tierras, cit., 76-7); y sobre todo en el interior coruñés con una media de 0,31 criados/hogar, $7 \%$ de la población y presencia en el 20,53\% de los hogares (SANDOVAL VEREA, Francisco, "Familia y explotación agropecuaria del interior coruñés a mediados del siglo XVIII", Obradoiro de Historia Moderna, $\mathrm{n}^{\circ}$ 7, [1998], 249-280). En la provincia de Ourense a mediados del siglo XVIII: 4,36\% de la población en el valle de Monterrei (GONZÁLEZ ABELLÁS, Isaac C., La comarca, cit., 145), 3,66\% en Celanova (RODRÍGUEZ FERNÁNDEZ, D., A terra, cit., 139), 4,79\% en Cea (LÓPEZ ALVAREZ, M.J., A terra, cit., 195). En 1584, en el coto mindoniense de Balboa había criados en el 18,42\% de sus 38 hogares. SAAVEDRA FERNÁNDEZ, Pegerto, Economía, cit., 125. En la Europa Noroccidental los criados estarían presentes en 1/3 de los hogares y supondrían un $10 \%$ de la población (citamos por SOBRADO CORREA, Hortensio, Las tierras, cit., 76)

${ }^{54}$ DUBERT GARCÍA, Isidro, Historia, 76. En comarcas ourensanas como Moterrei 63,5\% (GONZÁLEZ ABELLÁS, I.C., La comarca, cit., 145).
} 
Tabla 5. Lugar de origen de los criados de la jurisdicción de San Clodio en 1580

\begin{tabular}{lrr}
\hline Lugar de origen & $\mathbf{N}^{\mathbf{0}}$ & $\mathbf{\%}$ \\
\hline núcleo de la Jurisdicción & 45 & 49,45 \\
\hline localidades limítrofes & 5 & 5,49 \\
\hline localidades próximas & 14 & 15,38 \\
\hline condado de Ribadavia & 7 & 7,69 \\
\hline localidades no próximas & 9 & 9,89 \\
\hline fuera de la jurisdicción & 11 & 12,09 \\
\hline Total casos & $\mathbf{9 1}$ & $\mathbf{1 0 0 , 0 0}$ \\
\hline
\end{tabular}

Tabla 6. Tiempo de permanencia de los criados en los hogares de la jurisdicción de San Clodio en 1580

\begin{tabular}{lrrr}
\hline meses & $\mathbf{N}^{\mathbf{0}}$ & $\mathbf{\%}$ & Media meses \\
\hline 1 a 6 meses & 35 & 41,67 & 3,17 \\
\hline 8 a 12 meses & 25 & 29,76 & 11,12 \\
\hline 18 a 36 meses & 15 & 17,86 & 30,80 \\
\hline 48 a 180 & 9 & 10,71 & 106,67 \\
\hline Total casos & $\mathbf{8 4}$ & $\mathbf{1 0 0 , 0 0}$ & $\mathbf{2 1 , 8 6}$ \\
\hline
\end{tabular}

El servicio doméstico contribuye decisivamente a que el tamaño medio del $23 \%$ de familias en las que está presente, con 5,49 individuos/hogar, sea muy superior al de la media del conjunto de la jurisdicción, y suele ser un indicador del mayor nivel de renta de las mismas ${ }^{55}$. La imposibilidad de reconstruir el ciclo vital de las familias a partir de las edades de los cabezas de casa nos impide conocer hasta qué punto los criados cubrían los déficits de fuerza de trabajo que se producían en los hogares de San Clodio a lo largo de ese ciclo vital, en relación con la mayor o menor presencia de hijos y nietos, tal y como se ha comprobado en otros trabajos ${ }^{56}$. En apariencia, en la foto fija de 1580 no se percibe esta dinámica ya que en las familias con criados también se documenta un aporte superior de hijos y de otros parientes de menor importancia porcentual como nietos o sobrinos. En todo caso, parece clara la relación de criados y renta, que respondería a una lógica homeostática en la que los hijos que abandonaban las casas más humildes para servir en las más pudientes, adelgazaban el hogar de origen y engrosaban el de destino. De este modo podían reunir un peculio que les ayudase, en el futuro, a constituir un hogar. Pero además, esta vía también sirvió a huérfanos desvalidos para huir de la miseria refugiándose como criados en hogares que le ofrecían sustento y estabilidad. En el padrón raras veces se indica la edad de los domésticos, pero con frecuencia se hace mención a su orfandad o al hecho de ser niños que las familias acogen y "crían

55 SOBRADO CORREA, Hortensio, A Galicia, cit., 152). En Galicia, esta relación entre servicio doméstico y nivel de renta ha sido contrastada con claridad para la comarca ourensana de Monterrei en GONZÁLEZ ABELLÁS, Isaac C., La comarca, cit., 145-52 y para el interior coruñes en SANDOVAL VEREA, Francisco, cit., "Familia, 265; También ha sido demostrada en otras latitudes como la Huerta valenciana PÉREZ GARCÍA, José Manuel, "La familia campesina en la Huerta de Valencia durante el siglo XVIII", Boletín ADEH, nº 2, 1988, p 5-28.

${ }^{56}$ DUBERT GARCÍA, Isidro, Historia, cit., 80 y ss; FERNÁDEZ CORTIZO, Camilo, "A una misma; SANDOVAL VEREA, Francisco, "Familia, cit., 264. 
"JUNTOS EN UNA CASA DEBAJO DEL PODERÍO PATERNAL": LA FAMILIA EN LA

por amor de Dios". En muchos de estos casos sus relaciones seguramente llegaron a ser más afectivas que laborales ${ }^{57}, \mathrm{y}$, de hecho, en varias ocasiones los criados son verdaderos parientes: hermanos, cuñados o sobrinos del cabeza de $\operatorname{casa}^{58}$.

En el padrón de 1580 se consigna la procedencia geográfica de poco más de la mitad $(55,49 \%)$ de este importante segmento de la población, pero los 91 casos en los que se indica pueden ser representativos del comportamiento global. El resultado obtenido revela que la gran mayoría son naturales de lugares relativamente próximos, cuando no de la misma localidad en la que sirven. Si tenemos en cuenta que la mitad $(49,45 \%)$ son originarios de las tres parroquias que integran el núcleo de la jurisdicción de San Clodio y que algo más del $30 \%$ lo son de localidades que se sitúan en un radio de 20 kilómetros ${ }^{59}$, la conclusión es que no recorren grandes distancias para buscar casa en la que servir (véase tabla 5). Tan sólo el 8,8\% procede de lugares relativamente lejanos de San Clodio, como A Peroxa, Verea, Lobios, O Covelo, A Cañiza, Bangueses, Araúxo, Deza o Portugal, sin que se pueda precisar la localidad de origen de un $12 \%$ de casos en los que sólo se indica que vienen de fuera de la jurisdicción. Por último, a partir de los 84 casos en los que el padrón informa del tiempo de permanencia de los criados en cada hogar se obtiene una media de 23 meses para los varones y de 20 meses para las mujeres, aunque cuatro de cada diez no superaban los seis meses de estancia en un mismo hogar y siete de cada diez no pasaban del año (véase tabla 4). Todo ello parece subrayar la movilidad laboral y el carácter provisional que tenía esta ocupación. Por el contrario, son reducidos los casos en los que se observa estabilidad en la misma casa: poco más del $10 \%$ superan los cuatro años de permanencia y sólo el $6 \%$ superan los diez años ${ }^{60}$.

$\mathrm{Si}$, como vimos, el sexo y estado civil del cabeza de casa condicionaban las características de la familia, su rango social y categoría profesional lo hacían en

\footnotetext{
57 No son infrecuentes las menciones de muchachos/as, en muchos casos huérfanos, acogidos en los hogares por caridad y en los que desempeñarían labores de criados: "Antonio Pérez do Outero y Ynes do Porto, su muger ... Tienen en su casa a una moça que se llama Maria que la crían por amor de Dios". Asiento 130 de Lebosende (FERNÁNDEZ GONZÁLEZ, Frutos, cit., O padrón, 191). La servidumbre como vía para reunir un peculio, así como el acogimiento de criados como "asistencia social" ha sido señalada para el interior de Lugo en SOBRADO CORREA, Hortensio, Las tierras, cit., 80-81, y en SAAVEDRA, Pegerto, Das casas, cit., 28.

58 Sobre parientes que corresiden en calidad de criados véase DUBERT GARCÍA, Isidro, Historia, cit., 18; SAAVEDRA, Pegerto. La vida, cit., 244; y RODRÍGUEZ FERNÁNDEZ, Delfina, A terra, cit., 139.

59 En ese radio de $20 \mathrm{~km}$ se situarían las localidades de parroquias limítrofes y próximas al núcleo jurisdiccional y las imprecisas menciones al condado de Ribadavia, como lugar de origen.

60 SOBRADO CORREA, Hortensio, Las tierras, cit., 81.
} 
la misma o mayor medida, ya que, como es bien sabido, patrimonio y status social están en estrecha relación con el tipo de hogar. Así, los nueve hogares de aquellos cabezas de casa catalogados en el padrón como hidalgos $(2,10 \%$ del total de familias) presentan un tamaño medio (6,22 individuos/hogar), notablemente superior a la media global, mientras en el otro extremo, los tildados de "pobres" (también el 2,10\% de fuegos), son en su práctica totalidad solitarios/as entre los que el número medio de miembros por hogar supera ligeramente la unidad. Como acabamos de ver al tratar del servicio doméstico, su aporte (1,56 criados/hogar) es fundamental para explicar el mayor tamaño medio de las familias hidalgas; un grupo social que está emergiendo como élite local y que habrá de experimentar un notable desarrollo en la comarca del Ribeiro en los dos siglos siguientes ${ }^{61}$. A diferencia de lo que ocurre en los hogares campesinos, en estas casas recae sobre los sirvientes todo el trabajo agrícola de unas explotaciones de mayor tamaño, así como las tareas propiamente domésticas de las que se ocuparían las criadas; de ahí la necesidad de mayor fuerza de trabajo asalariado en estos hogares, al margen de su valor simbólico como signo de rango social. Por las mismas razones los curas de Lebosende y Bieite cuentan con abundante servicio doméstico (entre los dos suman seis criados/as), aunque el estado célibe de los clérigos y, en estos dos casos, la ausencia de otros corresidentes en sus hogares, tan solo los lleva a superar ligeramente el tamaño medio de las familias de la jurisdicción. Como ya se indicó, el hecho de que en el padrón no aparezcan los residentes en el Monasterio nos hurta la posibilidad de conocer el número de criados con los que contaban los monjes de San Clodio a finales del XVI y que, sin duda, contribuirían a incrementar ligeramente el peso relativo de la servidumbre ${ }^{62}$.

Las pocas familias cuyo jefe varón se ocupaba en actividades complementarias o extraagrarias $(9,81 \%)$ también presentan un tamaño medio ligeramente

61 Los integrantes de estas familias -excluidos los criados- suman el 2,60\% de la población de la jurisdicción de San Clodio en 1580. Sobre el mayor tamaño de las familias hidalgas: SOBRADO CORREA, Hortensio, A Galicia, cit., 153. Sobre la emergencia y desarrollo de la hidalguía gallega MIGUÉS RODRÍGUEZ, Vítor M., As terras, as pousas e os vinculeiros. A fidalguía galega na Época Moderna, Sada-A Coruña, 2002; y PRESEDO GARAZO, Antonio, A fidalguía galega. Estudos sobre a reprodución social dos fidalgos na Galicia Moderna, Santiago de Compostela, 2008.

62 En 1753 a los 18 monjes y 3 novicios que residían en el Monasterio de San Clodio les acompañaban 9 criados "a todos los quales mantiene y tiene para su servicio dentro", es decir el 30\% del total de la "familia" monástica, (Libro personal de eclesiásticos de Sta. Mª de San Clodio, AHPOu, Delegación Provincial del Ministerio de Hacienda de Orense, L. 2177), cifra que duplica a la documentada para la totalidad de los cistercienses gallegos (15,74\%) en 1797 (REY CASTELAO, Ofelia, "El servicio doméstico del clero regular gallego a fines de la Edad moderna", en Galicia monástica: estudos en lembranza da profesora María José Portela Silva, Santiago de Compostela, 2009, 289-310). 
superior a la media $(4,22)$, debido a que los hogares de escribanos, carpinteros, sastres y zapateros registran un mayor aporte de hijos y servicio doméstico ${ }^{63}$. Si en el caso de los sastres $(4,57)$ es decisivo el número de criados, en el de los carpinteros $(4,33)$ y zapateros $(5,14)$ es más significativa la prole, y en el de los escribanos $(6,80)$, ambos motivos ${ }^{64}$. Por el contrario, los hogares de las mujeres que ejercen un oficio -una tendera, una tejedora y tres costureras; mujeres solteras o viudas, entre las que tres aparecen acompañada por un hijopresentan un tamaño medio $(1,67)$ muy por debajo de la media. Que sólo se declare el oficio de las mujeres solitarias induce a pensar que el padrón omite la ocupación de las que no siendo cabezas de casa, también pudieran ejercer actividades complementarias de la labranza. Aunque en realidad, esta afirmación también puede hacerse extensiva a los varones, puesto que, salvo en el caso de los cabezas de casa, parece que, en general, se omitió ese dato ${ }^{65}$.

\section{Estructuras FAmiliares y EXPlotación Agraria}

La concordancia del tamaño medio de los hogares de San Clodio de finales del siglo XVI con el de mediados del siglo XVIII oculta acusadas diferencias estructurales entre una y otra época ${ }^{66}$. Si en la última fecha los hogares de la parroquia de San Clodio con estructura nuclear representaban el 65\% del total, en 1580 su predominio era muy superior $(79,67 \%)$ en el conjunto de la jurisdicción, y

\footnotetext{
${ }^{63}$ Se documentan 7 sastres, 7 zapateros, 5 canteros, 5 escribanos, 3 carpinteros, 3 soldados, 3 costureras, 2 barberos, 1 herrero, 1 herrador 1, fundidor, 1 cerrajero, y 1 cirujano, 1 tendera, 1 tejedora. Los hogares de los canteros y del cerrajero se encuentran en la línea de la media global, mientras los restantes (salvo escribanos, carpinteros, sastres y zapateros) se sitúan por debajo de esa media. No se incluyeron en el cómputo ni al párroco de Lebosende ni al capellán de Bieite que presentan hogares de 5 y 3 miembros, respectivamente. Sobre el mayor tamaño y aporte de criados en este tipo de hogares SAAVEDRA FERNÁNDEZ, Pegerto, Economía, cit., 128, y SOBRADO CORREA, Hortensio, "Economía campesina, prácticas sucesorias desigualitarias y familia troncal en la Galicia de la Edad Moderna", Obradoiro de Historia Moderna, nº 7, 1988, (201-224).

${ }^{64}$ Dos escribanos (Alonso y Gonzalo Rodríguez de Araújo, vecinos del lugar y parroquia de San Clodio, (asientos 25 y 27) pertenecen a una de las familias de la emergente hidalguía local. El primero reúne en su casa a 12 personas. FERNANDEZ GONZÁLEZ, Frutos, O padrón, cit., 195.

65 Resulta significativo el caso del lugar de Ponte San Clodio. En el padrón de 1580 no se documenta actividad extraagraria para ninguno de los 17 vecinos, a pesar de que se trataba de un barrio eminentemente comercial. De hecho, el tumbo de 1607 del Monasterio de San Clodio recoge diversos foros para tiendas y da noticias de las ferias y mercados que se celebraban en este lugar. AHN, Clero, Códice 424B.

${ }^{66}$ Para el análisis de las estructuras familiares partimos de la clasificación de Laslett (LASLETT, Peter, "Introduction: History of the Family" en Household and Family in Past Time, Cambridge, 1972, 28 e ss.) tanto por su mayor versatilidad con relación a otras, como por su utilidad a efectos comparativos, si bien con ligeras adaptaciones que la ajustan a la realidad gallega (descendente tipo A, y de solteras y solteros con hijos) ya introducidas por DUBERT, Isidro, Historia, cit., 96.
} 
muy reducida la presencia de las familias complejas $(3,27 \% \text {, véase tabla } 7)^{67}$. Entre las familias de estructura nuclear, que aglutinaban en su seno a cerca del $90 \%$ de la población, las más habituales eran las parejas conyugales con hijos; tanto, que suponían algo más de la mitad de todas las familias asentadas en el padrón $(50,70)$. Este último tipo de familia, que por su importancia numérica podría ser la tipo del territorio estudiado, presenta, sin embargo, un tamaño medio (5 individuos/hogar) superior a la media global. Esto es debido, no sólo a la presencia universal de cónyuge ( 1 por familia) e hijos $(2,53)$, sino también a un significativo aporte de servicio doméstico $(0,47)$. Por el contrario, el peso de las parejas conyugales sin hijos es mucho menor y, al igual que el grupo de viudas con hijos, se mueve en torno al $12 \%$ del total de familias. La otra cara de la moneda son los viudos con hijos, minoritarios $(3,70 \%)$ por las razones ya apuntadas, y los hogares constituidos por solteras con hijos $(2,34 \%)$, generalmente mujeres de pocos recursos, ocupadas en ocasiones en actividades complementarias como costureras o tejedoras. Por último, sólo se documentan dos varones solteros con hijos, una excepción que tan sólo supone el 0,47\% del total de familias.

Gráfico 2. Tamaño y aportes del hogar según su estructura interna en la jurisdicción de San Clodio en 1580.

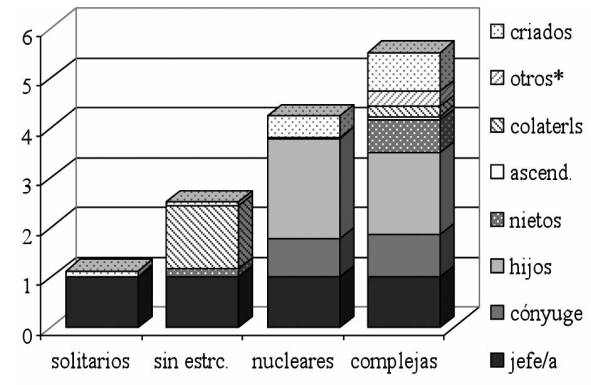

Gráfico 3. Distribución de los distintos tipos de estructuras familiares en la jurisdicción de San Clodio en 1580

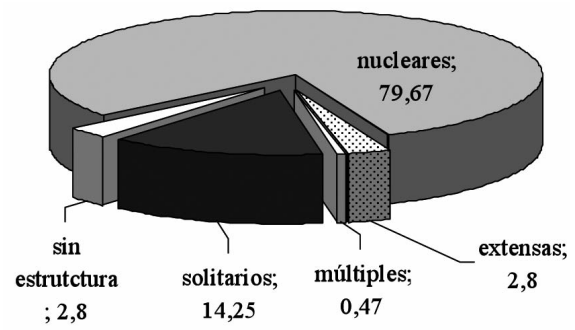

${ }^{67}$ Pegerto Saavedra ha calculado el dato de la parroquia de San Clodio que, juntamente con las de Gomariz y Beade, presentan el siguiente reparto de estructuras familiares para la comarca del Ribeiro en 1753: 5,92\% solitarios, 8,15\% sin estructura, 66,67\% nucleares, $4,07 \%$ extensos y $15,19 \%$ múltiples (SAAVEDRA, Pegerto, Das casas, 31). En el conjunto de la provincia de Ourense de mediados del siglo XVIII, las estructuras nucleares se mueven entre el 60\% y el 70\% (Ibídem, 29; RODRÍGUEZ FERNÁNDEZ, Delfina, A terra, 133; LÓPEZ ÁLVAREZ, Mª José, A terra, cit., 198; GONZÁLEZ ABELLÁS, Isaac C., La comarca, cit., 135). 
“JUNTOS EN UNA CASA DEBAJO DEL PODERÍO PATERNAL": LA FAMILIA EN LA

JURISDICCIÓN DE SAN CLODIO DO RIBEIRO DE AVIA A FINALES DEL SIGLO XVI

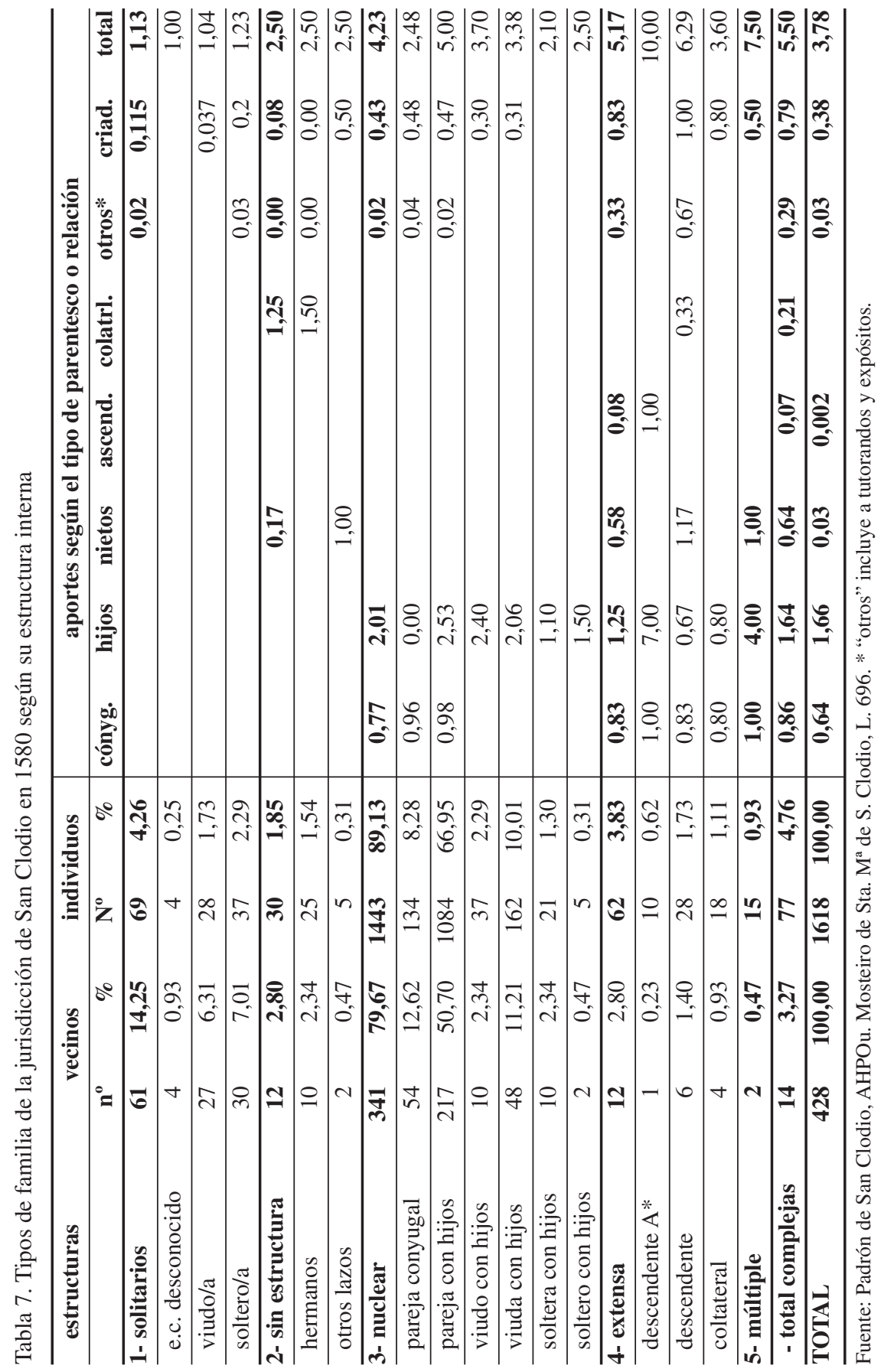

Cuadernos de Estudios Gallegos, LVIII, N. ${ }^{\circ}$ 124, enero-diciembre (2011), 197-234. ISSN 0210-847 X 
Los solitarios son el segundo grupo con mayor representación $(14,25 \%)$, y, si bien se encuentran a mucha distancia de los nucleares, su notable presencia contribuye a reducir el tamaño medio del conjunto de los hogares de la jurisdicción. Curiosamente, su peso casi triplica a la cata realizada en el Ribeiro a mediados del siglo XVIII por P. Saavedra y duplica al que se registra para toda Galicia a mediados del siglo XVIII (8,8\%); no obstante, se encuentra próximo a las cifras obtenidas para la Galicia meridional y, en concreto, para varias comarcas ourensanas en esa misma fecha ${ }^{68}$. Que el tamaño medio de estos hogares supere ligeramente la unidad se debe a la infrecuente compañía de servicio doméstico; de hecho se puede observar que es en este grupo en el que el aporte de criados es más reducido, y que estos se concentran en los hogares de una viuda y de los curas de Biete y Lebosende. Por tanto, en general, son hogares de cortos recursos en los que el padrón advierte a menudo su condición de pobres. El equilibrio entre la proporción de solitarios/as solteros/as (7,01\%) y solitarios/as viudos/as $(6,31 \%)$ oculta los contrastes interiores de estos dos grupos (véase tabla 7). Así, si atendemos solamente al sexo del cabeza de casa, se observa que las jefaturas masculinas de solitarios solteros cuatriplican a las de los viudos solitarios, mientras en las jefaturas de solitarias femeninas, las viudas duplican a las solteras. La frecuencia de segundas nupcias, como vimos mucho mayor entre los hombres, puede ser uno de los factores explicativos de este contraste, en un contexto en el que los solteros tienen que competir desfavorablemente con los viudos en el mercado matrimonial $^{69}$. Mientras, la soledad femenina, ya sea por soltería, viudez o abandono del marido -voluntario o forzado por razones económicas-, es sinónimo de pobreza y desamparo ${ }^{70}$. Los grupos domésticos sin estructura familiar son un

\footnotetext{
68 A mediados del siglo XVIII se observa contraste en este punto entre la Galicia septentrional y la meridional. En concreto en la provincia de Ourense se supera ampliamente el 13\% (DUBERT GARCÍA, Isidro, Historia, cit., 90-93). La cifra más elevada de solitarios se registra en Celanova (11,33\%, RODRÍGUEZ FERNÁNDEZ, Delfina, A terra, cit., 133), mientras en Monerrei (9\%, GONZÁLEZ ABELLÁS, Isaac C., La comarca, cit., 137) y Cea (8,9\% ÁLVAREZ, Mª José, A terra, cit., 183) es algo más reducida. Una vez más, el contrapunto lo pone el interior de Lugo, donde los solitarios solo suman el 6,6\% (4,8\% sin clero) debido a que buena parte de los hermanos/as solteros/as continuaban viviendo en el hogar del vinculeiro: SOBRADO CORREA, Hortensio, Las tierras, cit., 87-8. En la cata realizada para el Ribeiro para esa fecha se obtienen cifras muy bajas (5,92\%): SAAVEDRA, Pegerto, Das casas, cit., 31.

69 REY CASTELAO, Ofelia "Mecanismos, cit., 250. El menor peso de las solteras contrasta con lo observado para la Galicia de mediados del siglo XVIII en la que las jefaturas de solteras suponen la mitad de los hogares de solitarios/as (DUBERT GARCÍA, Historia, cit., 90)

${ }^{70}$ De las nueve personas calificadas de pobres (6 mendigantes), siete son mujeres y son muy elocuentes los casos que se documentan el padrón, como el del asiento 39 de Lebosende, citado en la nota 42, o el de Adega Guerra, "muger soltera y baldia. No tiene casa ni biña ni hacienda sino lo que pide por Dios, y se mantiene dello" (asiento 39 de Leiro), FERNÁNDEZ GONZÁLEZ, Frutos, O padrón, cit., 167. Sobre la feminización de la pobreza durante la Edad Moderna REY CASTELAO, Ofelia, y RIAL GARCÍA, Serrana, Historia, cit., 196 y ss.
} 
tipo poco representativo y, en general, se trata de familias en las que la pareja conyugal ha desaparecido prematuramente, y en las que los hijos permanecen agrupados solos o bajo la custodia del pariente más cercano, como es el caso de las abuelas viudas. En ocasiones, estos huérfanos pueden ser menores que, pese a vivir autónomamente, están sometidos a tutela o curatela de algún otro vecino de cuyo nombre y vecindad informa el padrón.

Por su parte, las catorce familias de estructura compleja suman, como dijimos, poco más del $3 \%$ y aglutinan al 4,76\% de la población. Se trata en su práctica totalidad de hogares de estructura extensa repartidos de forma igualitaria entre descendentes y colaterales, con un tamaño medio que alcanza los 5,50 individuos/familia. Entre las familias de estructura extensa, originadas en su mayoría por la presencia de nietos y colaterales, se documenta el único caso de una ascendente que acompaña a su hijo cabeza de casa -la madre "pobre" de Lorenzo do Porto-, circunstancia que el redactor del padrón consideró necesario justificar, seguramente por su rareza ${ }^{71}$. De manera que la corresidencia de parientes ajenos al núcleo conyugal parece tratarse más de una excepción originada por razones de urgencia económica, que de una práctica habitual. Por el contrario y como suele ser habitual, el servicio doméstico es más numeroso en las familias complejas ( 0,79 criados/hogar) que en la media global, lo que también parece apuntar a que cuentan con patrimonios más crecidos que la media. Dentro de este grupo, los hogares de estructura múltiple tienen una presencia residual y también parecen responder a situaciones coyunturales muy específicas: los dos casos documentados lo constituyen un núcleo conyugal acompañado por una hija viuda y el hijo de esta y otro núcleo con un hijo soltero que tiene bajo su custodia a "un hijo que le ubo con una moça soltera"72. Es decir que no existe ni un sólo hogar en el que convivan dos núcleos conyugales.

La relación entre las características demográficas de la familia con las dimensiones del patrimonio es ya un tema clásico entre los historiadores gallegos ${ }^{73}$.

\footnotetext{
${ }^{71}$ En el caso de la viuda que vive con su hijo se explica que esta convivencia se debe a la situación de pobreza de la madre, lo que parece querer incidir en la excepcionalidad del caso (registro 55 de Lebosende): "El dicho Lorenzo do Porto tiene en su casa a Francisca Rodriguez, biuda, su madre, porque es pobre" (FERNÁNDEZ GONZÁLEZ, Frutos, O padrón, cit., 55). Obsérvese que el aporte de los corresidentes declarados como criados se computaron en el apartado de estos, pues como tales aparecen en el padrón. Los sobrinos (descendentes colaterales) que no se declaran como criados fueron sumados con el aporte de los colaterales, aunque originan hogares de estructura descendente colateral. También hay que recordar que en las extensas colaterales los hermanos y cuñados del cabeza de casa que las originan son declarados como criados, y en ese aporte fueron incluidos.

72 Asientos 47 y 4 de Lebosende: FERNÁNDEZ GONZÁLEZ, Frutos, O padrón, 179 y 173.

${ }^{73}$ Entre otros: FERNÁNDEZ CORTIZO, "Estrategias, cit.; PÉREZ GARCÍA, José Manuel, "La familia campesina, cit.; SOBRADO CORREA, Hortensio, Las tierras, cit., 85; SANDOVAL VEREA, Francisco, "La familia, cit.; GONZALEZ ABELLÁS, Isaac C., La comarca, cit., 145.
} 
Es posible conocer el tamaño aproximado de las explotaciones de la parroquia de San Clodio de la segunda mitad del siglo XVI a través del apeo de 1565. De sus datos resulta un tamaño medio de 1,1 Ha de viña por vecino ${ }^{74}$, a la que habría que sumarle unas 0,5 Ha de monte, de donde sacaban leña para consumo y esquilmo para abonar las viñas, y unas $0,1 \mathrm{Ha}$ de huertas y heredades para siembra de diversos productos destinados al consumo propio ${ }^{75}$. Como al apeo sólo lo separan tres lustros del padrón de 1580, ha sido posible identificar las propiedades que tenían 40 de las familias que aparecen en el padrón quince años antes, para comparar la extensión de esas propiedades con el tamaño de esas familias en 1580; siendo conscientes de que el desajuste cronológico entre padrón y apeo también puede desacompasar la relación entre el tamaño de la explotación y la fisonomía de la familia. Aún así, de esta comparación se pueden extraer dos conclusiones principales: las familias con más miembros se corresponden con las que disponen de mayor superficie de viña -entre las seis que superan los ocho miembros, solamente una dispone de menos de 3 Ha de viña, concretamente 1,3 Ha-; las familias con poca superficie de viña acostumbran a ser de menores dimensiones -de las 15 familias que tienen 20 cavaduras $^{76}$ de viña o menos $(0,86$ Ha), diez tenían 4 o menos miembros, y entre las cinco que los superan, dos cabezas de familia eran canteros, uno carpintero y de los otros dos se ignora si se dedicaban a alguna otra actividad-. Aunque donde mejor se observa esta correlación entre tamaño del hogar y superficie de viña aforada es en el caso de la naciente hidalguía; familias que habían conseguido foros muy amplios y en condiciones ventajosas de los monjes de San Clodio entre finales del siglo XV y principios del XVI y que en los dos siglos sucesivos seguirán engrosando sus patrimonios. Son claros los ejemplos de los hogares del escribano Alonso Rodríguez de Araújo (12 miembros en 1580) o de la del hidalgo Vasco Rodríguez de Nóvoa y Araújo (9 miembros), ambos descendientes de Vasco Rodríguez "el viejo" a quien el Monasterio concedió importantes foros a finales del siglo $\mathrm{XV}^{77}$. Como ya se ha indicado, en estas familias hidalgas el servicio doméstico tiene una presencia más destacada, precisamente para suplir la mayor necesidad de fuerza de trabajo que imponen unas explotaciones más grandes ${ }^{78}$. En este punto, no está de más recordar que los criados son el aporte humano que más flexibilidad le otorga al grupo doméstico en su ajuste con el tamaño de la explotación,

\footnotetext{
74 FERNÁNDEZ GONZÁLEZ, Frutos, O padrón, 46.

75 Datos de elaboración propia a partir de LÓPEZ FERNÁNDEZ, Cesáreao, Fuentes, cit., 77.

761 cavadura equivale a 4,37 áreas, FERNÁNDEZ JUSTO, Ma Isabel, La metrología tradicional gallega. Aportación a los estudios sobre el medio rural, Madrid, 1986, T. I, 322.

77 LUCAS ÁLVAREZ Manuel y LUCAS DOMÍNGUEZ, Pedro, El Monasterio, cit., documentos $n^{\circ}$ 634, 635 de la colección diplomática y R. 385.

${ }^{78}$ Se estima que en las casas hidalgas y de escribanos del Ribeiro, el servicio doméstico suponía el 6,9\% de la población a mediados del siglo XVIII, SAAVEDRA, Pegerto, Das casas, cit., 27.
} 
"JUNTOS EN UNA CASA DEBAJO DEL PODERÍO PATERNAL": LA FAMILIA EN LA

ya sea como vía de salida para los hijos que no se pueden ser sostenidos en su hogar de origen o para engrosar aquellos otros que tienen déficit de fuerza de trabajo.

\section{Conclusiones}

La reducida presencia de las estructuras troncales y el predominio aplastante de las nucleares quizá sean los rasgos que más distingan a la familia de San Clodio de finales del siglo XVI; sobre todo si se la compara con los casos que conocemos para mediados del siglo XVIII, incluido el del Ribeiro de Avia. Sin embargo, esta singularidad quizá no lo fuese tanto si contásemos con más ejemplos coetáneos. Abandonadas desde hace tiempo las teorías del supuesto proceso de simplificación de las estructuras familiares en el trayecto que va desde la Edad Media hasta las sociedades industriales, algunos autores han apuntado la posibilidad de un camino inverso a lo largo de la Edad Moderna ${ }^{79}$. Este proceso podría haber supuesto tanto un incremento de los hogares complejos como un engrosamiento del tamaño de las familias, o sólo lo primero. Pegerto Saavedra intuye una evolución de ese tipo a partir de algunas fuentes de la provincia de Mondoñedo, y aunque la limitada información procedente del padrón del coto de Balboa de 1584 no le permita una conclusión definitiva que incluya el siglo XVI, sí parecen ir en esa dirección los cambios que percibe entre 1631 y 1753 en el Concejo de Viveiro. Lo mismo se observa en otros trabajos que han comparado el Padrón Calle-Hita de 1708 con los libros personales del Catastro de Ensenada ${ }^{80}$. En el caso de O Salnés y O Morrazo se habría producido un incremento de hogares complejos, pero, a diferencia de Terra de Montes, sin engrosamiento del tamaño de las familias ${ }^{81}$. Por su parte, Hortensio Sobrado ha constatado como el paradigma hereditario del interior lucense -que privilegia a un heredero sobre los demás para evitar la disgregación de unas explotaciones amplias pero de bajos rendimientos- dió lugar al predominio de los hogares troncales a mediados del siglo XVIII. Sin embargo, ese sistema hereditario no fue estable en el tiempo,

79 En Galicia apuntó por primera vez que el incremento de la población no simplificaba los hogares FERNÁNDEZ CORTIZO, Camilo, “A una misma, 238-276. La refutación de la creencia en un proceso de simplificación de los hogares en el tránsito a las sociedades industriales es, entre otras, una de las aportaciones de Peter Lasslet: LASLETT, Peter, "Introduction, cit., 16 y ss; MOLL BLANES, Isabel, "Peter \& Laslett: Contexto y aportación (1915-2001)", en GARCÍA GONZÁLEZ, Francisco (coord.) La historia, cit., 29-44; y CHACÓN JIMÉNEZ, Francisco, "Prólogo", en Ídem, 9-22.

80 FERNÁNDEZ CORTIZO, Camilo, “A una misma, cit., p. 249-250. SOBRADO CORREA, Hortensio, Las tierras, cit., 393-399, PÉREZ GARCÍA, José Manuel, "Familias y hogares, cit., 71; SAAVEDRA FERNÁNDEZ, Pegerto, Economía, cit. 125-127.

81 PÉREZ GARCÍA, José Manuel, "Familias y hogares, cit., 71. FERNÁNDEZ CORTIZO, Camilo, "A una misma, cit. 
sino que evolucionó desde un reparto más igualitario en el siglo XVI hacia la rigidez de mediados del XVIII para, de nuevo, flexibilizarse durante el XIX; y ese proceso, junto a otros factores, afectó a la fisonomía familiar, favoreciendo el incremento de los hogares complejos conforme se imponía el sistema de mejora larga y, en sentido contrario, cuando se suavizó durante el XIX ${ }^{82}$.

Pero, aunque los estudios de la familia rural del Antiguo Régimen establecen relaciones entre los rasgos estructurales del grupo doméstico, las características del sistema agrario y el sistema hereditario, ni el sentido de esas relaciones está siempre claro ni cual de los tres factores es más determinante ${ }^{83}$. De hecho, sistemas agrarios de carácter extensivo como los del interior de las actuales provincias de Lugo y Ourense no dieron lugar a prácticas hereditarias idénticas, y sus respectivas tipologías familiares distaban mucho de parecerse a mediados del siglo $\mathrm{XVIII}^{84}$. Aun así, el profesor Saavedra considera que, entre los factores mencionados, lo más relevante para las características de las familias ourensanas de mediados del siglo XVIII sería el predominio del reparto más o menos igualitario. Esto habría auspiciado la creación de hogares neolocales y, por tanto, la superioridad de los hogares nucleares ${ }^{85}$. De hecho, en el apeo del Monasterio de San Clodio de 1565 son frecuentes los casos de declarantes que manifiestan ser herederos de los posesores originales del foro, ya finados, y en los que los bienes forales han sido divididos en partes iguales, lo que también indicaría que -a dife-

82 En el interior de Lugo, si en 1753 casi el 50\% de los hogares eran complejos, cien años más tarde se habían reducido al $30 \%$ y a la mitad a final del siglo XIX: SOBRADO CORREA, Hortensio, Las tierras, cit., 394-416.

${ }^{83}$ FERNÁNDEZ CORTIZO, Camilo, "Estrategias; SAAVEDRA, Pegerto, Das casas, cit., 39 y ss; PÉREZ GARCÍA, José Manuel, "La familia campesina, cit. ; SOBRADO CORREA, Hortensio, Las tierras, cit., 393 y ss., etc.

${ }^{84}$ Sobre la evolución de la tipología del grupo doméstico véase SOBRADO CORREA, Hortensio, Las tierras, cit., p. 395 y ss.; SAAVEDRA FERNÁNDEZ, Economía, cit. p. 125; y del mismo autor, La vida, cit., 162; y "Las lógicas, cit. 143.

85 SAAVEDRA, Pegerto, Das casas, cit., 260.

86 "La quinta parte del lugar que fincó de Francisco do Penedo, difunto, sito en la aldea da Varouta y las otras partes que llevan Graviel do Penedo e Maria do Penedo y Juan do Penedo e Lucia do penedo hijos que quedaron de Francisco do Penedo", correspondiente a la declaración de Pedro Raposo de la Barouta. AHPOu, Mosteiro de Sta. M ${ }^{a}$ de San Clodio, L 714. El sistema hereditario ourensano y su relación con la tipología familiar en SAAVEDRA, Pegerto, Das casas, cit., 39-43 y 47-8. Sin embargo, las monografías comarcales ourensanas referidas a mediados del siglo XVIII matizan esta imagen a partir de las escrituras notariales, observando junto al reparto igualitario una apreciable presencia de la mejora corta y muy reducida de la mejora larga en Celanova y Monterrei con más relevancia de esta última modalidad en Cea (33,69): RODRÍGUEZ FERNÁNDEZ, Delfina, A terra, cit., 142-143; LÓPEZ ÁLVAREZ, Ma José, A terra, 213; aunque Isaac C. GONZÁLEZ ABELLÁS (La comarca, cit., 136 y 155) relaciona el predominio de la nuclearidad de Monterrei con el predominio del reparto igualitario. Además, es posible que una parte de este tipo de herencia haya quedado oscurecido por no haber pasado ante notario. Sobre los obstáculos del sistema foral al reparto de las herencias en Lugo véase SOBRADO CORREA, Hortensio, Las tierras, cit., 403. 
"JUNTOS EN UNA CASA DEBAJO DEL PODERÍO PATERNAL": LA FAMILIA EN LA

rencia del interior lucense- los contratos forales no fueron obstáculo para el reparto $^{86}$.

Es muy probable que esto hubiese estimulado la proliferación de nuevos fuegos, en detrimento de los hogares patrilocales y complejos, pero no pueden obviarse otras circunstancias que, además, ayudarían a explicar la mayor presencia de hogares complejos $(19,26 \%)$ documentada a mediados del siglo XVIII en O Ribeiro $^{87}$. Los datos del tumbo de 1607 del Monasterio de San Clodio referidos al siglo XVI son un claro indicador de la etapa expansiva que vivía en esa época la economía del Ribeiro, debido sobre todo a la fuerte demanda que tenían sus vinos en diversos mercados gallegos, españoles y europeos, sin olvidar la procedente de las Armadas de la época de los Austrias ${ }^{88}$. Por su parte, la organización de diversas ferias en el entorno del Monasterio, la construcción del puente sobre el río Avia, costeado por los monjes, y la formación y rápido crecimiento de la localidad de Ponte San Clodio, son hechos que no hacen más que corroborar esa favorable coyuntura económica y demográfica. La facilidad para obtener nuevos foros del Monasterio en este próspero contexto, también tuvo que contribuir a esa creación de nuevos hogares, ya fuese por parte de los naturales del lugar o a través del establecimiento de inmigrantes. Una tasa de nupcialidad del 9,5 por mil para la parroquia de San Clodio entre 1570 y 1590 señala en esa dirección ${ }^{89}$. Por su parte, el libro de bautizados de la misma feligresía revela unas tasas de natalidad del 47 por mil durante el mismo período ${ }^{90}$; y si bien no disponemos de las cifras de mortalidad -ya que no contamos con el libro de difuntos- todo apunta a un régimen demográfico todavía joven, sin claros signos de autorregulación, y en fase expansiva.

Pegerto Saavedra ha puesto de relieve la fuerza de las prácticas comunitarias en el rural ourensano, favorecidas, entre otras cosas, por el mayor tamaño de sus aldeas $^{91}$. Esto podría explicar no sólo el alto porcentaje de solitarios de la juris-

\footnotetext{
87 Las estructuras familiares el Ribeiro en 1753 calculada a partir de los libros personales de legos del Catastro de Ensenada de la parroquias de San Clodio, Gomariz y Beade en SAAVEDRA, Pegerto, Das casas, cit., 31.

88 Entre estos mercados destacaban los de Pontevedra y Santiago, los de las ciudades de toda la cornisa cantábrica y en el exterior los de Flandes e Inglaterra: HUETZ DE LEMPS, Alain, "Auge y decadencia de un viñedo de calidad: el de Ribadavia" en Anuario de Historia Económica y Social, I (1986), 207-225. Sobre la demanda de las Armadas FERNÁNDEZ GONZÁLEZ, F.(2006): “O viño de Ribadavia nas Grandes Armadas" en Boletín Avriense, XXXVI, (2006), 143-166.

89 Tasa media anual calculada con los datos de casados en la parroquia de San Clodio entre los años 1570 y 1590 (Archivo Histórico Diocesano de Ourense. Libros Sacramentales de la parroquia de San Clodio. Sign. 22-15-1-I) y la población que registra el padrón de 1580.

90 Tasa media anual calculada con los datos de bautizados en la parroquia de San Clodio. AHDO, Libros Sacramentales de la parroquia de San Clodio. Sign. 22-15-1-I.

91 SAAVEDRA, Pegerto, Das casas, cit., 2-3.
} 
dicción de San Clodio, en particular de viudas, sino que también sería otra de las razones del reducido número de hogares complejos a finales del siglo XVI, ya que en este hábitat de núcleos de poblamiento de tamaño considerable y otros pequeños muy próximos entre si, como era el caso de San Clodio, la atención a los mayores podría ser más factible sin necesidad de la convivencia bajo el mismo techo, como también ha señalado J. M. Pérez García ${ }^{92}$. Por la misma razón sería más viable la vida en soledad de un buen número de célibes que bien podrían dedicarse al jornal en las variadas tareas que exige la viña a lo largo del año (poda, rodriga, cava, vendimia, ...), o, en el caso de los varones, ocuparse en las grandes obras promovidas en esta época por el Monasterio.

A finales del siglo XVIII la sociedad de San Clodio ya no era aquel mundo de oportunidades. A través del Censo de Floridablanca de 1787 sabemos que en esta fecha los mecanismos de autorregulación demográfica eran claros: emigración masculina, retraso de la edad de matrimonio tanto en hombres como en mujeres, mayor tamaño medio de las familias, etc. ${ }^{93}$. Desconocemos cual era el grado de influencia de estos mecanismos de autorregulación a mediados del siglo XVIII, pero habida cuenta de la saturación demográfica que se observa $-200 \mathrm{hab} / \mathrm{km}^{2}$ en el núcleo de la jurisdicción, tras dos siglos de altas tasas de natalidad-, el establecimiento de hogares neolocales tenía que resultar más difícil que en el siglo $\mathrm{XVI}^{94}$, con el consiguiente aumento de estructuras complejas. Además, para entender este presumible aumento de hogares complejos, tampoco debe olvidarse el incremento numérico y la acumulación patrimonial que experimentó la hidalguía entre una y otra fecha. Si este grupo social jugó un papel fundamental en la articulación de la sociedad gallega del Antiguo Régimen, -particularmente en las comarcas vitícolas, en las que las rentas forales eran mucho más substanciosas-, ese papel tuvo especial relevancia en el Ribeiro del Avia, donde se registra una las mayores concentraciones de esta elite local a finales del Antiguo Régimen ${ }^{95}$. Los hidalgos, al tener vinculados sus bienes, practicaban una transmisión patrimonial de heredero único que daba lugar a hogares complejos e integrados, ade-

\footnotetext{
92 PÉREZ GARCÍA, José Manuel, "Familias y hogares, cit., 74.

${ }^{93}$ Esto es lo que se desprende de los datos relativos a la jurisdicción de San Clodio en SAAVEDRA, Pegerto, Das casas cit., 37; tamaño familiar en p. 36, celibato y edad al matrimonio (26,41 en hombres y 26,62 en mujeres) en p. 69, relaciones de masculinidad en p. 72. En el mismo sentido las cifras que aporta RODRÍGUEZ RODRÍGUEZ, Juan M., "Evolución, cit., 110 y ss. en relación a todo el Ribeiro de Avia.

${ }^{94}$ Estas restricciones impuestas a la fundación de nuevos hogares que llevan a la reducción de las estructuras nucleares y el incremento de las complejas ha sido señalada para O Salnés y O Morrazo del mediados del siglo XVIII "que incrementaron la complejidad pero no el tamaño de los hogares": PEREZ GARCÍA, José Manuel, "Familias y hogares, cit., 70.

${ }^{95}$ Sobre lo substancioso de las rentas del Ribeiro y la rentable incardinación de la hidalguía en el sistema foral: SAAVEDRA, Pegerto, Das casas, cit., 222-3.
} 
más, por un mayor número de criados que la media. Por eso, el desarrollo de este grupo privilegiado -que pasó del 2,23\% de los vecinos laicos en 1580 al 12,75\% a mediados del siglo XVIII en el núcleo de la jurisdicción ${ }^{96}$-, también debió incidir en el mayor peso de los hogares troncales registrados en la última fecha, al margen del mayor o menor efecto mimético que este modelo familiar hubiese podido producir en familias no hidalgas ${ }^{97}$. En conclusión, la próspera coyuntura económico-demográfica del siglo XVI, junto a un sistema hereditario igualitario habrían incentivado la creación de hogares neolocales, lo que explicaría la hegemonía de las familias con estructura nuclear en la jurisdicción de San Clodio en 1580. Pero el incesante crecimiento demográfico que se registra desde el siglo $\mathrm{XVI}^{98}$ y la mayor presencia de familias hidalgas habrían ido reduciendo el peso de ese tipo de hogares y cooperando al incremento de los complejos. Sin embargo esto apenas se tradujo en un aumento del tamaño medio de los hogares de San Clodio, seguramente a causa del abundante número de solitarios, otro destacado rasgo del sistema familiar de la provincia de Ourense a mediados del siglo XVIII ${ }^{99}$.

Los acusados contrastes internos de la Galicia rural del Antiguo Régimen desaconsejan las generalizaciones, de manera que las conclusiones de este trabajo son exclusivamente aplicables al marco físico al que se refieren los datos del padrón de San Clodio de 1580. Sin embargo, no habrán de pasarse por alto los paralelismos con el citado padrón de 1584 del pequeño coto mindoniense de Balboa, a partir del cual Pegerto Saavedra extrajo algunas impresiones que pueden ser aplicables a la familia de San Clodio de finales del siglo XVI -"abundancia de viudas, de personas que van y vienen, de mujeres que han tenido hijos de diferentes padres, de huérfanos, de casos en los que los hijos no viven todos bajo el mismo techo"- y que lo lleva a la percepción de una estructuras familiares poco consistentes $^{100}$. Seguramente futuros trabajos podrán ampliar territorialmente la información que actualmente tenemos acerca de la familia gallega del siglo XVI y arrojar algo más de luz sobre un periodo todavía oscuro en esta materia.

\footnotetext{
96 Elaboración propia a partir de los datos de los libros personales de legos del Catastro de Ensenada de las parroquias de Bieite, San Clodio y Lebosende. El peso de la hidalguía era todavía mayor del que reflejan las cifras del Catastro de Ensenada de estas parroquias, si se tiene en cuenta que buena parte de los forasteros que declaran tierras en las mismas son hidalgos empadronados en otras localidades pero que residían una parte del año en el pazo que poseían en la jurisdicción de San Clodio, tal y como se documenta a través de otras fuentes.

97 La imitación de los modelos familiares de la hidalguía por parte del campesinado se ha apuntado para el interior de Lugo SOBRADO CORREA, Hortensio, Las tierras, 415.

98 RODRÍGUEZ RODRÍGUEZ, Juan M., "Evolución, cit.

99 DUBERT GARCÍA, Isidro, Historia, cit., 93.

100 SAAVEDRA FERNÁNDEZ, Pegerto, Economía, cit., 125.
} 


\section{BIBLIOGRAFÍA CITADA}

CASTIÑEIRA CASTRO, Víctor M., "O fogar no extremo occidental da Costa da Morte (17501850)" en Historia Nova VI e VII: Contribución dos Xoves Historiadores de Galicia, Santiago, 1999, 145-167.

CHACÓN JIMÉNEZ, Francisco, "Prólogo", en GARCÍA GONZÁLEZ, Francisco (coord.), La historia de la familia en la Península Ibérica. Balance regional y perspectivas «Homenaje A Peter Laslett», Cuenca, 2008, 9-22.

-, y HERNÁNDEZ FRANCO Juan (eds.), Espacios sociales, universos familiares. La familia en la historiografía española. Murcia, 2007.

DUBERT GARCÍA, Isidro, Los comportamientos de la familia urbana en la Galicia del Antiguo Régimen. El ejemplo de Santiago de Compostela, Santiago, 1987.

-, Historia de la familia en Galicia durante la época moderna, 1550-1830: estructura, modelos hereditarios y conflictividad. A Coruña-Sada, 1992.

EIRAS ROEL, Antonio, La población de Galicia, 1700-1860. Crecimiento, distribución espacial y estructura de la población de Galicia en los siglos XVIII y XIX, Santiago de Compostela, 1996, 25-27.

- (coord.), El reino de Galicia en la monarquía de Felipe II, Santiago de Compostela, 1998.

FAYA DÍAZ, Ma Ángeles, "Jurisdicciones de los monasterios cistercienses gallegos a mediados del S. XVI", en Actas Congreso Internacional sobre San Bernardo e o Cister en Galicia e Portugal, Ourense, 1992, Vol. 1, 289-308.

- "Los señoríos eclesiásticos gallegos y la venta de jurisdicciones en tiempos de Felipe II", en V Reunión Científica de la Asociación Española de Historia Moderna, Vol. 1, Cádiz, 1999, 101-116.

FERNÁNDEZ CORTIZO, Camilo, "A una misma mesa y manteles: la familia en Tierra de Montes en el siglo XVIII", en Cuadernos de Estudios Gallegos, XXXIII (1982), 237276.

- "En casa y compañía: grupo doméstico y estrategias familiares na Galicia occidental a mediados del siglo XVIII", en BERMEJO BARRERA, J.C. (coord.), Parentesco, familia y matrimonio en la Historia de Galicia, 1989, 145-165.

_"Estrategias familiares y pequeña explotación campesina en la Galicia del siglo XVIII", en SAAVEDRA, Pegerto, y VILLARES, Ramón (eds.), Señores y campesinos en la Península Ibérica, siglos XVIII-XX. 2. Campesinado y pequeña explotación, Barcelona, 1991, 310345.

- "«Aldeas y caserías a tiro de mano de piedra»: los asentamientos rurales en el arzobispado de Santiago (siglos XVI-XVIII)", Espacio, Tiempo y Forma, Serie IV, H. Moderna, t. 7, (1994), 211-226.

- "La Galicia rural en tiempos de Felipe", en EIRAS ROEL, Antonio (coord.), El reino de Galicia en la monarquía de Felipe II, Santiago de Compostela, 1998, 345-378.

- "El señorío rural gallego en tiempos de Felipe II" en EIRAS ROEL, Antonio (coord.), El reino de Galicia en la monarquía de Felipe II, Santiago de Compostela, 1998, 379408.

FERNÁNDEZ GONZÁLEZ, Frutos, "Aproximación al Abadologio del Monasterio de San Clodio do Ribeiro", en Actas III Congreso Internacional sobre el Cister en Galicia y Portugal, Vol. I, Ourense, 2006, 95-121. 
"JUNTOS EN UNA CASA DEBAJO DEL PODERÍO PATERNAL": LA FAMILIA EN LA JURISDICCIÓN DE SAN CLODIO DO RIBEIRO DE AVIA A FINALES DEL SIGLO XVI

- O padrón de San Clodio de 1580. Estudo histórico e onomástico, Santiago de Compostela, 2008.

FERNÁNDEZ JUSTO, Ma Isabel, La metrología tradicional gallega. Aportación a los estudios sobre el medio rural, Madrid, 1986.

FERREIRA PRIEGUE, Elisa, Galicia en el comercio marítimo medieval, A Coruña, 1988.

FERREIRO PÉREZ, Rosa, La Alta Limia en los siglos XVII y XVIII. Muestreo parroquial, Santiago, 1981, (memoria de licenciatura inédita).

FLANDRIN, J-L., Orígenes de la familia moderna, Barcelona, 1979.

GARCÍA GONZÁLEZ, Francisco (coord.), La historia de la familia en la Península Ibérica. Balance regional y perspectivas «Homenaje A Peter Laslett», Cuenca, 2008.

GELABERT, Juan E., Santiago y la Tierra de Santiago de 1500 a 1640: contribución a la Historia Económica y Social de los territorios de la Corona de Castilla en los siglos XVI y XVII, Sada-A Coruña, 1982.

GONZÁLEZ ABELLÁS, Isaac César, La comarca de Monterrei en el Antiguo Régimen. Economía, demografía y familia, Santiago de Compostela, 2010.

HUETZ DE LEMPS, Alain, Vignobles et vins du Nord-Ouest de l'Espagne, Burdeos, 1967.

-“Auge y decadencia de un viñedo de calidad: el de Ribadavia” en Anuario de Historia Económica y Social, I (1986), 207-225.

LASLETT, Peter, "Introduction: History of the Family" en Household and Family in Past Time, Cambridge, 1972, 1-158.

LÓPEZ ÁLVAREZ, M ${ }^{\mathrm{a}}$ José, A terra de Cea no antigo réxime. Formas de vida nunha comarca de transición ourensá, Ourense, 2007.

LÓPEZ DÍAZ, María, "Alteraciones en el mapa jurisdiccional gallego durante la Edad Moderna: las desmembraciones eclesiásticas del siglo XVI", Estudios Mindonienses, $\mathrm{n}^{\circ} 7$, (1991), 559-588.

LÓPEZ FERNÁNDEZ, Cesáreo, Fuentes para el Estudio del Monasterio de San Clodio del Ribero de Avia. Apeos de 1565, Santiago de Compostela, 1976, (memoria de licenciatura inédita).

LUCAS ÁlVAREZ Manuel, y LUCAS DOMÍNGUEZ, Pedro, El Monasterio de San Clodio do Ribeiro en la Edad Media: estudio y documentos, Sada-A Coruña, 1996.

MARTÍNEZ RODRÍGUEZ, Enrique, "La población en la Galicia de Felipe II", en EIRAS ROEL, Antonio (coord.), El reino de Galicia en la monarquía de Felipe II, Santiago de Compostela, 1998, 441-472.

MIGUÉS RODRÍGUEZ, Vítor M., As terras, as pousas e os vinculeiros. A fidalguía galega na Época Moderna, Sada-A Coruña, 2002.

MOLL BLANES, Isabel, "Peter \& Laslett: Contexto y aportación (1915-2001)”, en GARCÍA GONZÁLEZ, Francisco (coord.) La historia de la familia en la Península Ibérica. Balance regional y perspectivas «Homenaje A Peter Laslett», Cuenca, 2008, 29-44.

PÉREZ GARCÍA, José Manuel, Un modelo de sociedad rural de Antiguo Régimen en la Galicia costera: la Península del Salnés (Jurisdicción de La Lanzada), Santiago de Compostela, 1979.

- "Familias y hogares en Galicia y en la Cornisa Cantábrica durante el Antiguo Régimen", en GARCÍA GONZÁLEZ, Francisco (coord.) La historia de la familia en la Península Ibérica. Balance regional y perspectivas «Homenaje A Peter Laslett», Cuenca, 2008, 57-84. 
PORTELA SILVA, Ermelindo, La colonización cisterciense en Galicia: (1142-1250), Santiago de Compostela, 1981.

PRESEDO GARAZO, Antonio, A fidalguía galega. Estudos sobre a reprodución social dos fidalgos na Galicia Moderna, Santiago de Compostela, 2008.

REY CASTELAO, Ofelia, "Mecanismos reguladores de la nupcialidad en la Galicia atlántica. El matrimonio a trueque", en Obradoiro de Historia Moderna: homenaje al profesor Antonio Eiras Roel en el XXV aniversario de su cátedra, 1990, 247-268.

-"El servicio doméstico del clero regular gallego a fines de la Edad moderna", en Galicia monástica: estudos en lembranza da profesora María José Portela Silva, Santiago de Compostela, 2009, 289-310.

-, y RIAL GARCÍA, Serrana, Historia de las mujeres en Galicia. Siglos XVI al XIX, Vigo, 2009.

RIONEGRO FARIÑA, Isolina, La estructura económica del Císter orensano en la fase final del Antiguo Régimen, Ourense, 1998.

RODRÍGUEZ FERNÁNDEZ, Delfina, A terra e as xentes. Nacer, vivir e morrer na comarca de Celanova ó longo da Idade Moderna, A Coruña, 1999.

-, "Aldeas y parroquias. La estructuración del territorio en la comarca celanovesa a lo largo de los tiempos modernos", en REBOREDA MORILLO, Susana (ed.), Homenaxe á profesora Lola F. Ferro: estudos de historia, arte e xeografía, Ourense, 2005, 536-555.

RODRÍGUEZ RODRÍGUEZ, Juan Manuel, "Evolución, Estructura y principales caracteres de la Población del Ribeiro de Avia", Cuadernos Feijonianos de Historia Moderna, n 1 , (1999), 87-131.

SAAVEDRA FERNÁNDEZ, Pegerto, Economía política y sociedad en Galicia: la provincia de Mondoñedo, 1480-1830. A Coruña, 1985.

- "Casa y comunidad en la Galicia interior, 1750-1860", en BERMEJO BARRERA, J.C. (coord.), Parentesco, familia y matrimonio en la Historia de Galicia, 1989, 95-143.

- "Contribución al estudio del régimen señorial gallego", Anuario de Historia del Derecho Español, nº 60, (1990), 103-184.

- Galicia. Historia. Tomo III. La Galicia del Antiguo Régimen. Economía y sociedad. A Coruña, 1991, 52 y ss.

- "Algúns problemas que presentan as fontes fiscais do século XVI do Arquivo Xeral de Simancas referidas a Galicia", en SAAVEDRA, Pegerto, A facenda Real na Galicia do Antigo Réxime, Santiago, 1993. 17-37.

- La vida cotidiana en la Galicia del Antiguo Régimen, Barcelona, 1994.

- Das casas de morada ó monte comunal, Santiago de Compostela, 1996.

- "A economía vitícola na Galicia do Antigo Réxime", en SAAVEDRA, Pegerto, Das casas de morada ó monte comunal, Santiago de Compostela, 1996, 213-269.

- "O hábitat no noroeste peninsular nos ss. XVI-XIX", en Espacios rurais e sociedades campesiñas, Semata, Ciencias Sociais e Humanidades, (1997), p.173-93.

- "Las lógicas de la organización familiar y reproducción social en la España cantábrica y noratlántica en el Antiguo Régimen", en Historia y perspectivas de investigación. Estudios en memoria del profesor Ángel Rodríguez Sánchez, Badajoz, 2002, 141-9.

SANDOVAL VEREA, Francisco, "Familia y explotación agropecuaria del interior corunés a mediados del siglo XVIII", Obradoiro de Historia Moderna, n 7, (1998), 249-280.

SOBRADO CORREA, Hortensio, "Economía campesina, prácticas sucesorias desigualitarias y familia troncal en la Galicia de la Edad Moderna", Obradoiro de Historia Moderna, ${ }^{\circ}$ 7, 1988, (201-224). 
“JUNTOS EN UNA CASA DEBAJO DEL PODERÍO PATERNAL": LA FAMILIA EN LA JURISDICCIÓN DE SAN CLODIO DO RIBEIRO DE AVIA A FINALES DEL SIGLO XVI

-, Las tierras de Lugo en la Edad Moderna: economía campesina, familia y herencia, 15501860, A Coruña, 2001.

- A gran Historia de Galicia. Tomo VI. A Galicia do Antigo Réxime (ca. 1480-ca. 1835). Poboación e economía. Vol. I, A Coruña, 2007. 147-203. 